\title{
CISTOS DE DINOFLAGELADOS DO HOLOCENO DA PLANÍCIE COSTEIRA DE SANTA CATARINA (POÇO PSC-03): DESCRIÇÕES TAXONÔMICAS E IMPLICAÇÕES PALEOAMBIENTAIS
}

\author{
HOLOCENE DINOFLAGELLATE CYSTS FROM THE SANTA CATARINA COAST PLAIN (CORE \\ PSC-03): TAXONOMIC DESCRIPTIONS AND PALEOENVIROMENTAL IMPLICATIONS
}

\author{
Wagner Guimarães da SILVA ${ }^{1,2}$, Paulo Alves de SOUZA ${ }^{2}$ \\ ${ }^{1}$ Instituto Federal de Educação, Ciência e Tecnologia do Rio Grande do Sul, IFRS, Campus Restinga, Rua Alberto Hoffmann, 285, \\ Porto Alegre, RS, Brasil. Email: wagner.guimaraes.silva@gmail.com \\ ${ }^{2}$ Programa de Pós-graduação em Geociências, Laboratório de Palinologia Marleni Marques Toigo, Instituto de Geociências, \\ Universidade Federal do Rio Grande do Sul. Avenida Bento Gonçalves, 9500, Porto Alegre, RS, Brasil. \\ Email: paulo.alves.souza@ufrgs.br

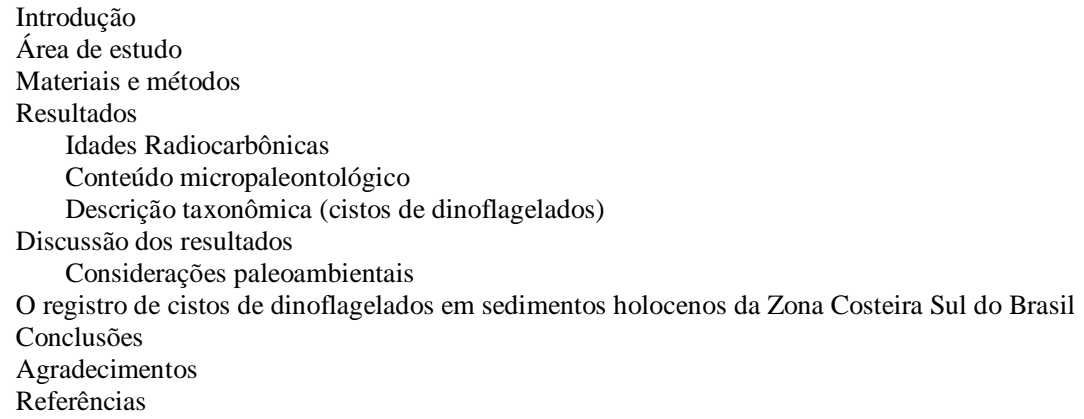

RESUMO - Estudos palinológicos de detalhe abordando cistos de dinoflagelados quaternários de depósitos sedimentares brasileiros são relativamente escassos. A análise palinológica de sedimentos do Holoceno do poço PSC-03 (2753'22"S; 48 39'04" W) perfurado na Planície Costeira de Santa Catarina, sul do Brasil, revelou associações palinológicas abundantes e diversificadas que incluem palinomorfos terrestres (esporos, grãos de pólen, fungos, algas de água doce) e marinhos (cistos de dinoflagelados, palinoforaminíferos). A não exposição das amostras a métodos agressivos, tais como oxidação e acetólise, durante o processamento laboratorial permitiu a recuperação de cistos da Família Protoperidiniaceae. Três gêneros (Brigantedinium, Lejeunecysta, Spiniferites.) e quatro espécies (Brigantedinium simplex, Selenopemphix nephroides, S. quanta, Operculodinium centrocarpum) de cistos de dinoflagelados são descritos e ilustrados aqui, constituindo uma das associações fósseis mais diversificadas do grupo para o Holoceno brasileiro. A associação de cistos de dinoflagelados sugere ambiente marinho marginal, com águas superficiais susceptíveis a variação de salinidade e alta concentração de nutrientes.

Palavras-chave: Cistos de dinoflagelados, Holoceno, Planície Costeira de Santa Catarina.

\begin{abstract}
Detailed palynological studies on dinoflagellate cysts from Brazilian Quaternary deposits are relatively scarce. The palynological analysis performed from Holocene sediment of the core PSC-03 (2753'22'S; 48 39'04" W), drilled on the Coastal Plain of Santa Catarina, southern Brazil, revealed diverse and abundant palynological associations, including terrestrial (spores, pollen grains, fungi, freshwater algae) and marine (dinoflagellate cysts and foraminiferal linings) palynomorphs. The non-exposure of the samples to aggressive techniques, such as oxidation and acetolysis, during the laboratorial processing allowed the recovery of cysts from the family Protoperidiniaceae. Three genera (Brigantedinium, Lejeunecysta, Spiniferites) and four species (Brigantedinium simplex, Selenopemphix nephroides, S. quanta, Operculodinium centrocarpum) of dinoflagellate cysts are described and illustrated herein, constituting one of the most diverse fossil associations of the group for the Brazilian Holocene. The dinoflagellate cysts as sociation suggest marginal marine environments, with susceptible to salinity variation and high concentration of nutrients in the surface waters. Keywords: Dinoflagellate cysts, Holocene, Coastal Plain of Santa Catarina.
\end{abstract}

\section{INTRODUÇÃO}

A zona costeira do Brasil, assim como as demais áreas litorâneas mundiais, foi afetada pelas variações do nível do mar durante o Quaternário. Diversas investigações, ao longo do litoral brasileiro, constataram a existência de distintos conjuntos de fácies sedimentares, descontínuas no tempo e no espaço, resultantes do deslocamento dos processos e dos ambientes de sedimentação (e.g. Kowsmann et al., 1977;
Suguio et al., 1985; Martin et al., 1993, 2003; Villwock \& Tomazalli, 1995; Corrêa \& Villwock, 1996; Corrêa et al., 1996).

Trabalhos de cunho palinológico foram desenvolvidos em diferentes setores da costa brasileira com o objetivo de reconstruir a vegetação, o clima e as condições ambientais relacionadas às flutuações do nível do mar (e.g. Lorscheitter \& Romero, 1985; Behling, 1996; 
Behling \& Negrelle, 2001; Ybert et al., 2001; Amaral et al., 2006, 2012; Cancelli, 2012; Lorente et al., 2014). Entretanto, a maioria dessas análises privilegiam os palinomorfos terrestres (grãos de pólens e esporos), com pouco aprofundamento taxonômico e de análise dos representantes marinhos (cistos de dinoflagelados, acritarcos, palinoforaminíferos, ovos de copépodes). Contribuições enfocando cistos de dinoflagelados e suas aplicações nas interpretações das mudanças ambientais no Quaternário brasileiro são conhecidas para a Bacia de Campos, embora ainda inéditas (Oliveira, 2003, 2011; Noronha, 2011; Souza, 2012).

Com relação aos cistos de dinoflagelados, sua abundância e distribuição estão diretamente relacionadas à produção primária e às condições físico-químicas da água de superfície, na zona fótica dos mares e oceanos (Prauss, 2000; de Vernal \& Marret, 2007; de Vernal et al., 2013). Segundo de Vernal \& Giroux (1991), cistos de dinoflagelados associados a grãos de pólen, esporos e outros microfósseis de parede orgânica podem ser utilizados como excelentes descritores para quantificar e qualificar o influxo de matéria orgânica nos depósitos sedimentares. Além disso, podem ser aplicados no estabelecimento de diferentes parâmetros d'água do mar, tais como salinidade, disponibilidade de nutrientes, produtividade primária, profundidade da coluna d'água e alterações das correntes marinhas (Wall et al., 1977; Edwards \& Andrle, 1992; Dale, 1996, 2009; Mudie \& Harland, 1996; Rochon et al., 1999; Marret \& Zonneveld, 2003; Matthiessen et al., 2005; Radi \& de Vernal, 2008; Zonneveld et al., 2013).

O objetivo deste trabalho é apresentar os cistos de dinoflagelados identificados no poço PSC-03 no setor central do litoral de Santa Catarina, sul do Brasil, com descrições, bem como suas implicações paleoecológicas e paleoambientais. Além disso, são apresentadas ocorrências quaternárias conhecidas do sul do Brasil, na tentativa de elucidar as causas da recuperação de associações de palinomorfos geralmente com pouca diversidade e quantidade de cistos de dinoflagelados.

\section{ÁREA DE ESTUDO}

Este trabalho foi desenvolvido a partir de amostras coletadas ao longo do poço PSC-03 perfurado no interior de uma mata à margem da rodovia BR $101(\mathrm{~km} 243$ - Sul, coordenadas
2753'22"S; 48³9'04" W), município de Palhoça, estado de Santa Catarina, sul do Brasil, distante cerca de $6 \mathrm{~km}$ da linha de costa atual (Figura 1).

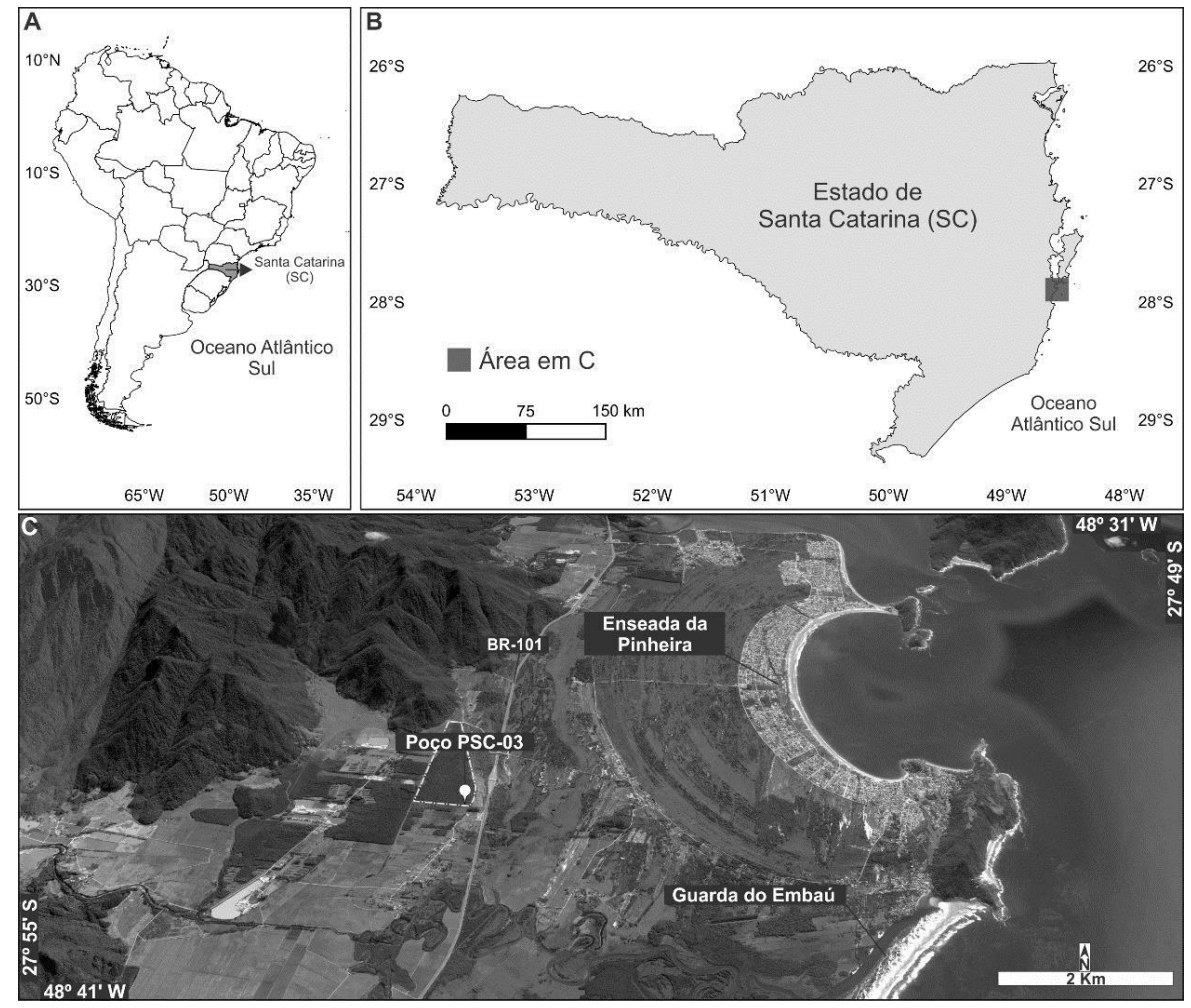

Figura 1. Localização da área de estudo na Planície Costeira de Santa Catarina (AB) e imagem de satélite com indicação do poço PSC-03 (C) (Fonte: Google Earth). 
A Planície Costeira de Santa Catarina (PCSC) compreende uma série de feições geomorfológicas e sistemas representados por depósitos sedimentares formados sob influência marinha, transicional e continental, diretamente relacionados às variações relativas do nível do mar durante o Quaternário. O município de Palhoça está inserido no Setor Central da PCSC, o qual é caracterizado por um complexo lagunar, composto por depósitos coluviais, aluviais, paludais e eólicos holocênicos (Horn Filho, 2003).

\section{MATERIAIS E MÉTODOS}

O poço PSC-03 atingiu uma profundidade de $300 \mathrm{~cm}$, é constituído por níveis de areia fina, intercalados com silte, com grande teor de matéria orgânica. Sessenta amostras com $3 \mathrm{~cm}^{3}$ cada, espaçadas a cada $5 \mathrm{~cm}$ entre si, foram extraídas para análise palinológica (Figura 2), processadas no Laboratório de Palinologia Marleni Marques Toigo, Instituto de Geociências, Universidade Federal do Rio Grande do Sul (LPMMT/UFRGS), conforme metodologia de Wood et al. (1996), incluindo particularidades propostas por Dale (1976). As amostras foram tratadas com ácidos (clorídrico e

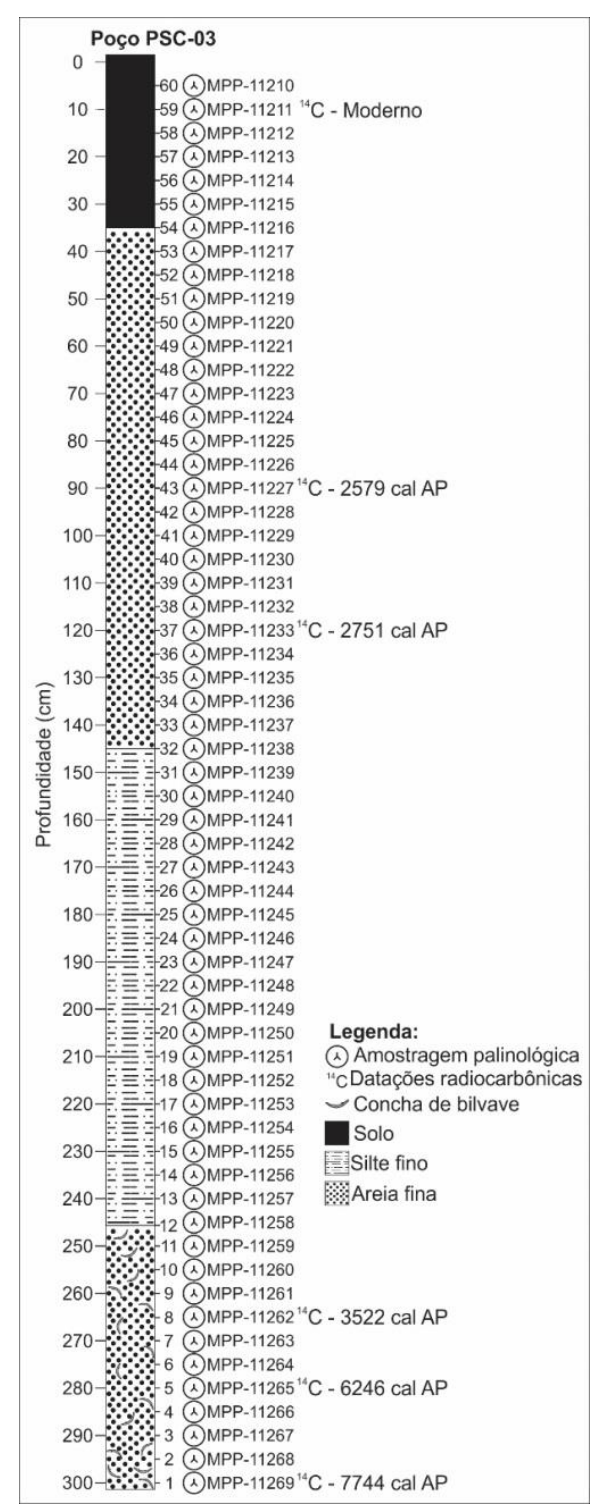

fluorídrico) a frio, não sendo submetidas a processos oxidativos ou acetólise, visando a preservação de cistos de dinoflagelados da Família Protoperidiniaceae. Em cada amostra foi adicionada uma pastilha de Lycopodium clavatum (Stockmarr, 1971) para fim de análise de concentração. Após a etapa de digestão ácida, o material resultante foi peneirado para concentração do resíduo palinológico entre 10 $\mu \mathrm{m}$ e $250 \mu \mathrm{m}$. Como resultado, uma lâmina foi confeccionada por amostra, as quais estão depositadas na Palinoteca do LPMMT/UFRGS, sob codificação MP-P (Figura 2).
Figura 2. Perfil estratigráfico do poço PSC-03, Holoceno da Planície Costeira de Santa Catarina mostrando a posição das amostras palinológicas, datações radiocar-bônicas, lâminas palinológicas e suas respectivas codificações (MPP: depositadas na Palinoteca do LPMMT/IG/UFRGS). 
Idades radiocarbônicas foram obtidas ao longo do poço, a partir de amostras selecionadas e analisadas no Laboratório CAIS (Universidade da Georgia, EUA), usando o Acelerador Espectrômetro de Massa (AMS). Para calibração das idades radiocarbônicas foi utilizado o software CALIB (Radiocarbon Calibration 7.1, Stuiver et al., 2016), levando em consideração a curva SHCal13 (Southern Hemisphere, Hoog et al., 2013).

A análise da frequência foi realizada a partir da contagem dos grupos constituintes dos palinomorfos (esporos, grãos de pólen, esporos de fungos, algas de água doce, cistos de dinoflagelados, palinoforaminíferos, tintino morfos). Contagens foram obtidas a partir da leitura total de cada lâmina, i.e. considerando todos os palinomorfos registrados. Frequências relativas $(\%)$ foram estabelecidas sobre o total de palinomorfos contados. O reconhecimento das características morfológicas e morfométricas dos microfósseis de parede orgânica foi realizado sob microscopia ótica de luz transmitida e luz azul incidente (luz fluorescente) em aumento de 1000 vezes.

Para a assignação taxonômica dos cistos de dinoflagelados foram consultados os trabalhos de Edwards \& Andrle (1992), Dale (1996), Rochon et al. (1999), Marret \& Zonneveld (2003), Zonneveld \& Pospelova (2015), ordenados segundo Fensome \& Williams (2004). O significado paleoecológico e paleoambiental foi extraído de Wall et al. (1977), Harland (1983), Edwards \& Andrle (1992), Dale (1996), Mudie \& Harland (1996), Rochon et al. (1999), Marret \& Zonneveld (2003), de Vernal et al. (2013) e Zonneveld et al. (2013), dentre outros.

\section{RESULTADOS}

\section{Idades radiocarbônicas}

As idades radiocarbônicas obtidas para as amostras selecionadas são apresentadas na tabela 1 e figura 2. Os resultados mostram que a deposição do poço ocorreu entre o Holoceno médio e tardio. A amostra basal foi datada em $7744 \mathrm{cal}$ AP $(300 \mathrm{~cm})$; as outras idades obtidas são respectivamente, $6246 \mathrm{cal} \operatorname{AP}(280 \mathrm{~cm}), 3522$ cal AP $(265 \mathrm{~cm}), 2751 \mathrm{cal} \mathrm{AP}(120 \mathrm{~cm}), 2579 \mathrm{cal}$
AP $(90 \mathrm{~cm})$; a amostra mais superior foi considerada moderna. Particularmente, a amostra a $155 \mathrm{~cm}$ de profundidade apresentou idade controversa em relação aos níveis superiores (Tabela 1), o que pode refletir evento de retrabalhamento de sedimentos mais antigos e mistura com os mais novos; dessa forma, a idade indicada neste nível não foi utilizada para o controle cronológico.

Tabela 1. Idades radiocarbônicas (AMS ${ }^{14} \mathrm{C}$ ) das amostras selecionadas do poço PSC-03, Holoceno da Planície Costeira de Santa e respectiva calibração. *O pMC (porcentagem de carbono moderno) é apresentado quando o material analisado tem mais ${ }^{14} \mathrm{C}$ que o padrão de referência moderno, assim esta amostra é considerada recente, ou seja pós 1950.

\begin{tabular}{|c|c|c|c|c|c|}
\hline $\begin{array}{l}\text { Número do } \\
\text { Laboratório }\end{array}$ & $\begin{array}{l}\text { Profundidade } \\
(\mathrm{cm})\end{array}$ & Idade ${ }^{14} \mathrm{C}$ AP & 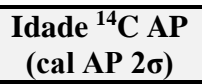 & $\begin{array}{c}\text { Idade calibrada AP } \\
\text { (média da probabilidade) }\end{array}$ & Material \\
\hline UGAMS \# 25848 & 10 & $100,85 \pm 0,3 \mathrm{pMC}^{*}$ & Moderno & ----- & Sedimento \\
\hline UGAMS \# 26518 & 90 & $2520 \pm 25$ & $2380-2721$ & 2579 & Madeira \\
\hline UGAMS \# 26983 & 120 & $2660 \pm 20$ & $2723-2777$ & 2751 & Sedimento \\
\hline UGAMS \# 23610 & 155 & $2230 \pm 250$ & $1606-2761$ & 2198 & Sedimento \\
\hline UGAMS \# 26517 & 265 & $3340 \pm 25$ & $3450-3607$ & 3522 & Sedimento \\
\hline UGAMS \# 26982 & 280 & $5490 \pm 25$ & $6195-6299$ & 6246 & Sedimento \\
\hline UGAMS \# 22214 & 300 & $6960 \pm 30$ & $7676-7832$ & 7744 & Sedimento \\
\hline
\end{tabular}

\section{Conteúdo micropaleontológico}

Três categorias de palinomorfos foram recuperadas: esporomorfos (esporos, grãos de pólen, fungos), fitoplâncton (algas de água doce e cistos de dinoflagelados) e zoomorfos (palinoforaminíferos e tintinomorfos), distribuídas em distintas quantidades ao longo do poço. Em termos gerais, esporos são predominantes $(27 \%-71 \%$, percentagens mínimas e máximas, respectivamente em todo o poço), ao lado de fungos (1\%-69\%), grãos de pólen (4\%-66\%), algas de água doce (1\%-47\%), cistos de dinoflagelados (1\%-42\%), palinoforaminíferos $(1 \%-18 \%)$ e tintinomorfos (1\%14\%). A listagem taxonômica e os dados de quantificação (contagem bruta e frequência relativa) são apresentados nas tabelas 2 e 3, respectivamente. A preservação dos palinomorfos é boa, com diferenças ao longo da seção, principalmente nos níveis basais, onde aqueles com parede rompida ou amassada são mais comuns; cristais de pirita aderidos à parede de determina-dos espécimes foram observados em diversos níveis. 
Tabela 2. Lista de palinomorfos identificados no poço PCS-03, Holoceno da Planície Costeira de Santa.

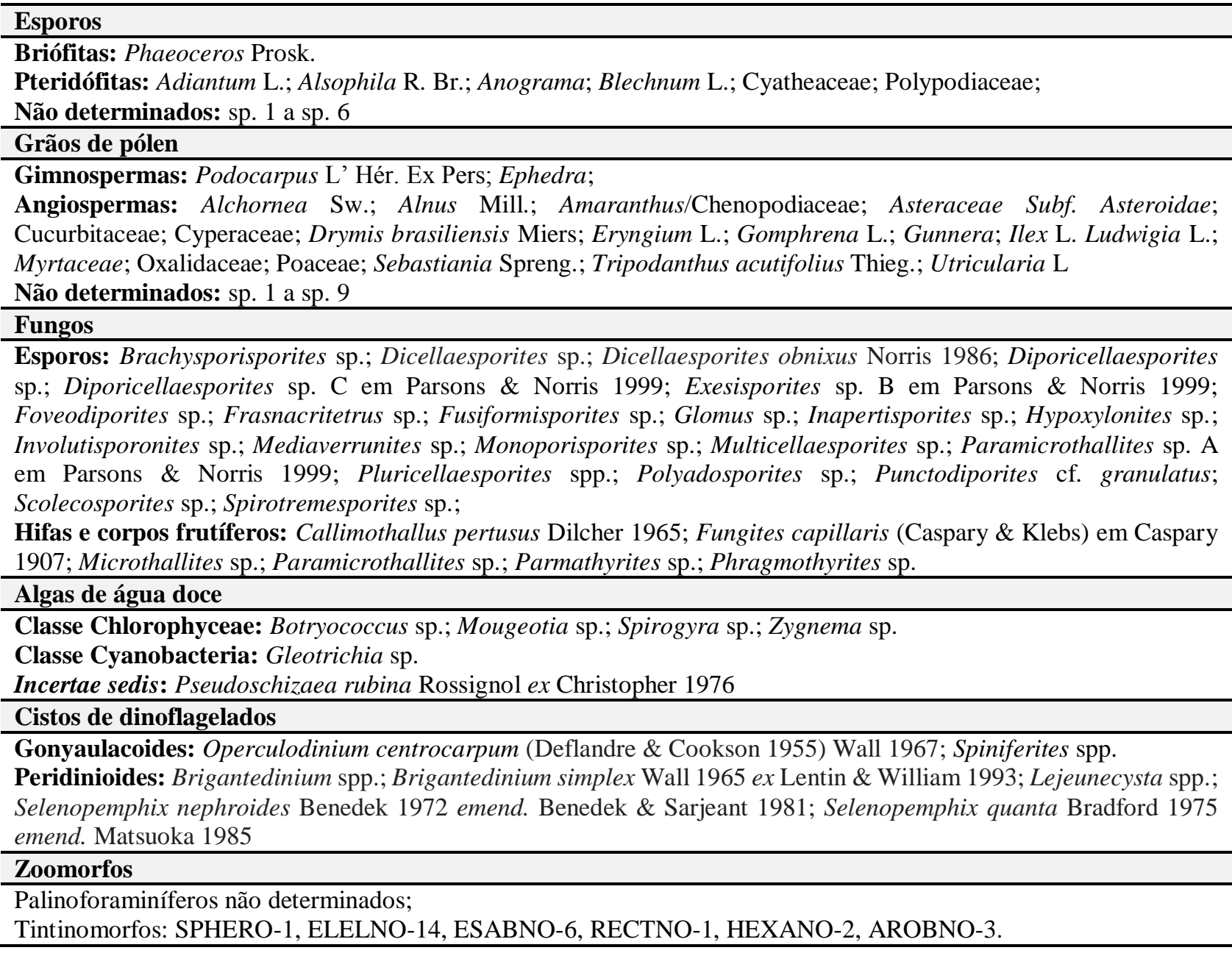

A maioria dos cistos de dinoflagelados ocorre em meio à matéria orgânica amorfa, principalmente aqueles representantes dos gêneros Operculodinium e Spiniferites. Por essa razão, a observação em microscópio óptico foi potencialmente facilitada com o auxílio de contraste de fase (DIC) e luz fluorescente.

Todos os gêneros e espécies de cistos de dinoflagelados identificados são descritos, com ilustrações apresentadas na figura 3, incluindo quatro espécies (Brigantedinium simplex, Selenopemphix nephroides, Selenopemphix quanta, Operculodinium centrocarpum) e designações abertas de três gêneros (Brigantedinium spp., Lejeunecysta spp., Spiniferites spp.). Os gêneros Spiniferites e Operculodinium são mais comuns e frequentes, registrados entre $300-150 \mathrm{~cm}$ de profundidade; subordinadamente foram reconhecidos os gêneros Brigantedinium, Selenopemphix e Lejeunecysta entre $295-175 \mathrm{~cm}$. A distribuição estratigráfica detalhada desses táxons é apresentada na figura 4. As descrições dos cistos de dinoflagelados são complementadas por informações ecológicas, paleoecológicas, paleoambientais e paleobiogeográficas, baseadas na compilação de dados da literatura, advinda de análogos modernos e ocorrências quaternárias dos respectivos táxons no Brasil e no exterior.

\section{Descrição taxonômica (cistos de dinoflagelados)}

Divisão DINOFLAGELLATA (Bütschli 1885)

Fensome et al. 1993

Classe DINOPHYCEAE Pascher 1914

Subclasse PERIDINIPHYCIDAE Fensome et al. 1993

Ordem PERIDINIALES Haeckel 1894

Subordem PERIDININEAE (autonímia)

Família CONGRUENTIDIACEAE Schiller 1935

Subfamília CONGRUENTIDIODEAE (autonímia)

Gênero Brigantedinium Reid 1977 ex Lentin \& William 1993

Brigantedinium simplex Wall 1965 ex Lentin \& William 1993

(Figura 3. A-B)

Descrição: cisto esferoidal de parede lisa, cor castanha; arqueopilo intercalar (2a), de forma hexagonal assimétrica, com lados aproximadamente equidimensionais. 
Tabela 3. Quantificação dos palinomorfos registrados no poço PCS-03, Holoceno da Planície Costeira de Santa. Contagem bruta (a) e frequência relativa (\%).

\begin{tabular}{|c|c|c|c|c|c|c|c|c|c|c|c|c|c|c|c|}
\hline \multirow{3}{*}{$\begin{array}{l}\text { Profundi- } \\
\text { dade } \\
\text { (cm) }\end{array}$} & \multicolumn{6}{|c|}{ Esporomorfos } & \multicolumn{4}{|c|}{ Fitoplâncton } & \multicolumn{4}{|c|}{ Zoomorfos } & \multirow{3}{*}{$\begin{array}{l}\text { Total de } \\
\text { Palino- } \\
\text { morfos }\end{array}$} \\
\hline & \multicolumn{2}{|c|}{ Esporos } & \multicolumn{2}{|c|}{$\begin{array}{c}\text { Grãos de } \\
\text { pólen }\end{array}$} & \multicolumn{2}{|c|}{ Fungos } & \multicolumn{2}{|c|}{$\begin{array}{l}\text { Algas de } \\
\text { água doce }\end{array}$} & \multicolumn{2}{|c|}{$\begin{array}{c}\text { Cistos de } \\
\text { dinoflagelados }\end{array}$} & $\begin{array}{r}P \\
\text { fora }\end{array}$ & íferos & Tinti & norfos & \\
\hline & (a) & $(\%)$ & (a) & $(\%)$ & (a) & $(\%)$ & (a) & $(\%)$ & (a) & $(\%)$ & (a) & $(\%)$ & (a) & $(\%)$ & \\
\hline 5 & 153 & 58 & 67 & 25 & 44 & 17 & 1 & 0 & 0 & 0 & 0 & 0 & 0 & 0 & 265 \\
\hline 10 & 144 & 53 & 92 & 34 & 34 & 13 & 0 & 0 & 0 & 0 & 0 & 0 & 0 & 0 & 270 \\
\hline 15 & 153 & 52 & 108 & 37 & 32 & 11 & 0 & 0 & 0 & 0 & 0 & 0 & 0 & 0 & 293 \\
\hline 20 & 116 & 32 & 157 & 43 & 74 & 20 & 20 & 5 & 0 & 0 & 0 & 0 & 0 & 0 & 367 \\
\hline 25 & 103 & 33 & 50 & 16 & 136 & 44 & 23 & 7 & 0 & 0 & 0 & 0 & 0 & 0 & 312 \\
\hline 30 & 69 & 24 & 22 & 8 & 183 & 63 & 17 & 6 & 0 & 0 & 0 & 0 & 0 & 0 & 291 \\
\hline 35 & 68 & 22 & 99 & 31 & 133 & 42 & 15 & 5 & 0 & 0 & 0 & 0 & 0 & 0 & 315 \\
\hline 40 & 40 & 12 & 199 & 61 & 78 & 24 & 8 & 2 & 0 & 0 & 0 & 0 & 0 & 0 & 325 \\
\hline 45 & 39 & 11 & 246 & 66 & 80 & 22 & 6 & 2 & 0 & 0 & 0 & 0 & 0 & 0 & 371 \\
\hline 50 & 79 & 21 & 173 & 46 & 118 & 31 & 5 & 1 & 0 & 0 & 0 & 0 & 0 & 0 & 375 \\
\hline 55 & 81 & 25 & 129 & 39 & 114 & 35 & 5 & 2 & 0 & 0 & 0 & 0 & 0 & 0 & 329 \\
\hline 60 & 116 & 41 & 96 & 34 & 40 & 14 & 29 & 10 & 0 & 0 & 0 & 0 & 0 & 0 & 281 \\
\hline 65 & 99 & 41 & 57 & 23 & 41 & 17 & 47 & 19 & 0 & 0 & 0 & 0 & 0 & 0 & 244 \\
\hline 70 & 103 & 45 & 45 & 19 & 39 & 17 & 44 & 19 & 0 & 0 & 0 & 0 & 0 & 0 & 231 \\
\hline 75 & 77 & 35 & 51 & 23 & 65 & 30 & 26 & 12 & 0 & 0 & 0 & 0 & 0 & 0 & 219 \\
\hline 80 & 42 & 14 & 34 & 12 & 208 & 71 & 7 & 2 & 0 & 0 & 0 & 0 & 0 & 0 & 291 \\
\hline 85 & 82 & 26 & 16 & 5 & 170 & 54 & 44 & 14 & 0 & 0 & 0 & 0 & 0 & 0 & 312 \\
\hline 90 & 32 & 12 & 10 & 4 & 188 & 69 & 41 & 15 & 0 & 0 & 0 & 0 & 0 & 0 & 271 \\
\hline 95 & 36 & 25 & 21 & 15 & 58 & 40 & 29 & 20 & 0 & 0 & 0 & 0 & 0 & 0 & 144 \\
\hline 100 & 26 & 21 & 24 & 19 & 41 & 33 & 34 & 27 & 0 & 0 & 0 & 0 & 0 & 0 & 125 \\
\hline 105 & 73 & 32 & 34 & 15 & 78 & 34 & 45 & 20 & 0 & 0 & 0 & 0 & 0 & 0 & 230 \\
\hline 110 & 45 & 29 & 17 & 11 & 64 & 42 & 28 & 18 & 0 & 0 & 0 & 0 & 0 & 0 & 154 \\
\hline 115 & 24 & 20 & 6 & 5 & 57 & 47 & 34 & 28 & 0 & 0 & 0 & 0 & 0 & 0 & 121 \\
\hline 120 & 31 & 21 & 14 & 9 & 60 & 41 & 43 & 29 & 0 & 0 & 0 & 0 & 0 & 0 & 148 \\
\hline 125 & 24 & 16 & 14 & 10 & 39 & 27 & 69 & 47 & 0 & 0 & 0 & 0 & 0 & 0 & 146 \\
\hline 130 & 30 & 13 & 14 & 6 & 77 & 34 & 107 & 47 & 0 & 0 & 0 & 0 & 0 & 0 & 228 \\
\hline 135 & 54 & 28 & 32 & 17 & 47 & 25 & 57 & 30 & 0 & 0 & 0 & 0 & 0 & 0 & 190 \\
\hline 140 & 44 & 27 & 26 & 16 & 63 & 38 & 33 & 20 & 0 & 0 & 0 & 0 & 0 & 0 & 166 \\
\hline 145 & 69 & 42 & 13 & 8 & 83 & 50 & 0 & 0 & 0 & 0 & 0 & 0 & 0 & 0 & 165 \\
\hline 150 & 38 & 44 & 15 & 17 & 32 & 37 & 0 & 0 & 1 & 1 & 1 & 1 & 0 & 0 & 87 \\
\hline 155 & 43 & 59 & 5 & 7 & 19 & 26 & 1 & 1 & 4 & 5 & 1 & 1 & 0 & 0 & 73 \\
\hline 160 & 46 & 62 & 1 & 1 & 4 & 5 & 0 & 0 & 21 & 28 & 2 & 3 & 0 & 0 & 74 \\
\hline 165 & 21 & 36 & 5 & 8 & 22 & 37 & 1 & 2 & 8 & 14 & 2 & 3 & 0 & 0 & 59 \\
\hline 170 & 44 & 54 & 16 & 20 & 5 & 6 & 0 & 0 & 15 & 18 & 2 & 2 & 0 & 0 & 82 \\
\hline 175 & 55 & 51 & 5 & 5 & 13 & 12 & 2 & 2 & 26 & 24 & 2 & 2 & 5 & 5 & 108 \\
\hline 180 & 41 & 71 & 3 & 5 & 7 & 12 & 0 & 0 & 3 & 5 & 2 & 3 & 2 & 3 & 58 \\
\hline 185 & 38 & 40 & 10 & 11 & 5 & 5 & 5 & 5 & 22 & 23 & 10 & 11 & 4 & 4 & 94 \\
\hline 190 & 19 & 46 & 2 & 5 & 3 & 7 & 0 & 0 & 16 & 39 & 1 & 2 & 0 & 0 & 41 \\
\hline 195 & 31 & 45 & 5 & 7 & 10 & 14 & 3 & 4 & 15 & 22 & 5 & 7 & 0 & 0 & 69 \\
\hline 200 & 24 & 44 & 4 & 7 & 11 & 20 & 0 & 0 & 11 & 20 & 2 & 4 & 3 & 5 & 55 \\
\hline 205 & 96 & 48 & 17 & 8 & 76 & 38 & 1 & 0 & 5 & 2 & 3 & 1 & 3 & 1 & 201 \\
\hline 210 & 51 & 51 & 14 & 14 & 12 & 12 & 0 & 0 & 16 & 16 & 2 & 2 & 5 & 5 & 100 \\
\hline 215 & 31 & 52 & 3 & 5 & 5 & 8 & 0 & 0 & 14 & 23 & 6 & 10 & 1 & 2 & 60 \\
\hline 220 & 24 & 28 & 18 & 21 & 20 & 23 & 1 & 1 & 20 & 23 & 3 & 3 & 0 & 0 & 86 \\
\hline 225 & 31 & 48 & 8 & 12 & 14 & 22 & 0 & 0 & 5 & 8 & 5 & 8 & 2 & 3 & 65 \\
\hline 230 & 31 & 58 & 4 & 8 & 8 & 15 & 0 & 0 & 4 & 8 & 4 & 8 & 2 & 4 & 53 \\
\hline 235 & 27 & 47 & 2 & 4 & 10 & 18 & 0 & 0 & 14 & 25 & 3 & 5 & 1 & 2 & 57 \\
\hline 240 & 13 & 52 & 1 & 4 & 4 & 16 & 0 & 0 & 4 & 16 & 3 & 12 & 0 & 0 & 25 \\
\hline 245 & 17 & 39 & 7 & 16 & 4 & 9 & 0 & 0 & 6 & 14 & 4 & 9 & 6 & 14 & 44 \\
\hline 250 & 30 & 61 & 7 & 14 & 3 & 6 & 0 & 0 & 3 & 6 & 5 & 10 & 1 & 2 & 49 \\
\hline 255 & 25 & 44 & 10 & 18 & 7 & 12 & 0 & 0 & 5 & 9 & 10 & 18 & 0 & 0 & 57 \\
\hline 260 & 17 & 26 & 18 & 27 & 10 & 15 & 1 & 2 & 14 & 21 & 3 & 5 & 3 & 5 & 66 \\
\hline 265 & 35 & 40 & 21 & 24 & 18 & 20 & 2 & 2 & 4 & 5 & 6 & 7 & 2 & 2 & 88 \\
\hline 270 & 24 & 32 & 19 & 25 & 9 & 12 & 1 & 1 & 17 & 22 & 5 & 7 & 1 & 1 & 76 \\
\hline 275 & 15 & 56 & 3 & 11 & 5 & 19 & 0 & 0 & 0 & 0 & 3 & 11 & 1 & 4 & 27 \\
\hline 280 & 15 & 27 & 12 & 22 & 2 & 4 & 0 & 0 & 23 & 42 & 3 & 5 & 0 & 0 & 55 \\
\hline 285 & 21 & 36 & 10 & 17 & 11 & 19 & 0 & 0 & 14 & 24 & 2 & 3 & 0 & 0 & 58 \\
\hline 290 & 11 & 48 & 5 & 22 & 3 & 13 & 0 & 0 & 2 & 9 & 2 & 9 & 0 & 0 & 23 \\
\hline 295 & 19 & 36 & 7 & 13 & 11 & 21 & 0 & 0 & 14 & 26 & 2 & 4 & 0 & 0 & 53 \\
\hline 300 & 12 & 32 & 14 & 38 & 10 & 27 & 0 & 0 & 1 & 3 & 0 & 0 & 0 & 0 & 37 \\
\hline
\end{tabular}




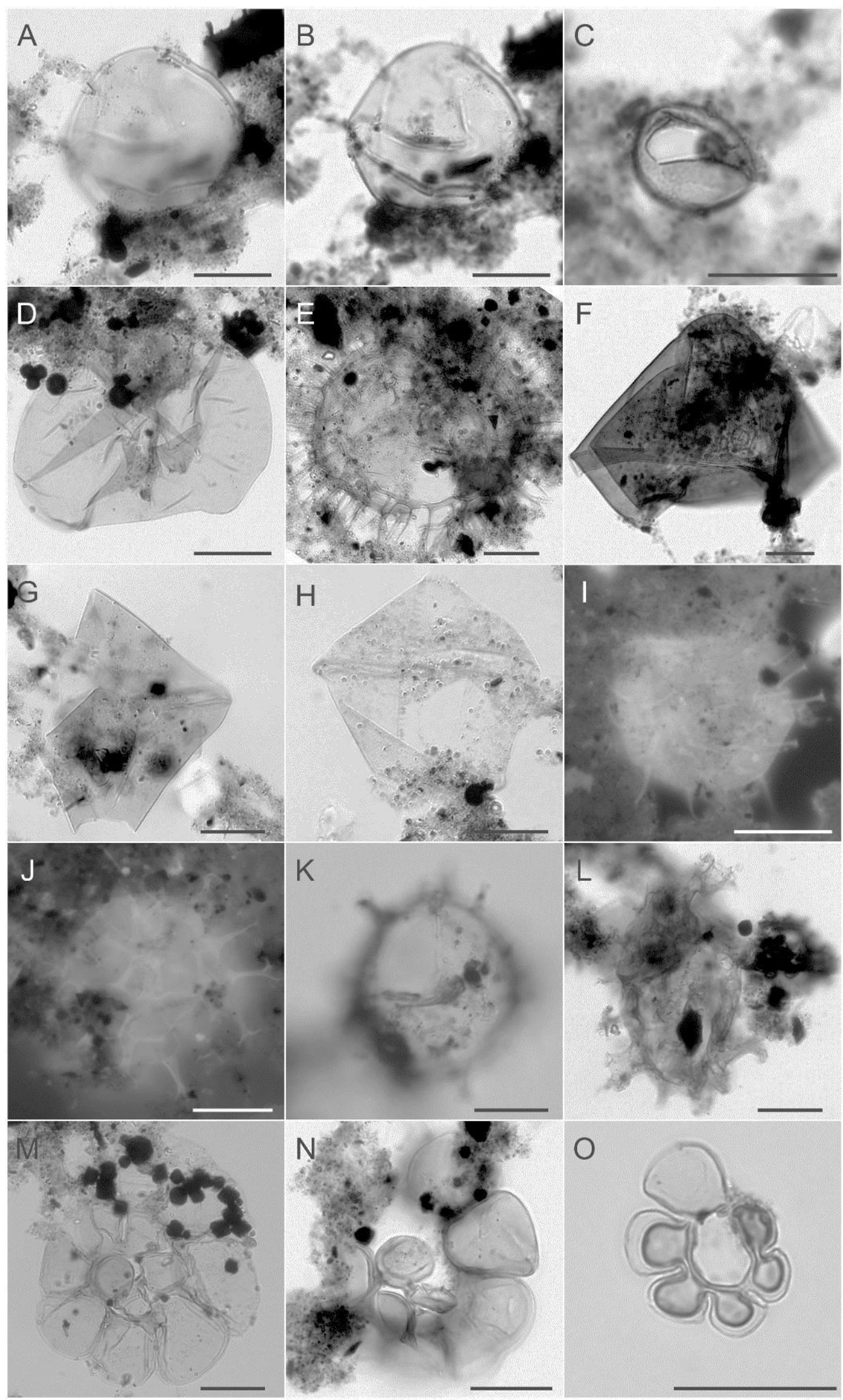

Figura 3. Fotomicrografias dos cistos de dinoflagelados e palinoforaminíferos registrados no poço PSC-03, Holoceno da Planície Costeira de Santa Catarina. A-B. Brigantedinium simplex (lâmina MPP: 11253, England Finder: B60-4); C. Brigantedinium sp. (11266, X54-4); D. Selenopemphix nephroides (11260, E61-4); E. Selenopemphix quanta (11256, J49); FH. Lejeunecysta spp. (11254, D42-2; 11262, Y33-2; 11244, N53-3); I. Operculodinium centrocarpum (fotomicrografia com luz florescente; 11268, C48); J-L. Spiniferites spp. (J. fotomicrografia com luz florescente;11250, W55; 11254, F63-3; 11257, X53-4); M-O. Palinoforaminíferos (11250, B62-3; 11264, G58-3; 11265, O43). Escala gráfica $20 \mu \mathrm{m}$. 
Dimensões (1 espécime): diâmetro do corpo central $42 \mu \mathrm{m}$.

Representante moderno: Protoperidinium conicoides (Paulsen 1905) Balech 1974.

Observações: registrado em sedimentos modernos de fácies nerítica interna do Atlântico Norte ao Ártico, abundante em latitudes maiores que $55^{\circ}$, em áreas onde a temperatura superficial d'água oscila entre $9^{\circ}$ a $14^{\circ} \mathrm{C}$ (Edwards \& Andrle, 1992; Matthiesses, 1995; Matthiesses et al., 2005). O estágio móvel de $B$. simplex ( $P$. conicoides) foi identificado em amostras da coluna d'água da plataforma e talude da Província de Buenos Aires e Terra do Fogo (Akselman, 1987). Considerada uma espécie cosmopolita e ocorrente em ambiente nerítico a oceânico (de Vernal et al., 2013). Na América do Sul, B. simplex foi identificada em amostras de plâncton, em sedimentos (modernos e do Holoceno) de diversas localidades da Argentina (Vilanova et al., 2008; Candel et al., 2009; Candel et al., 2012, 2013), geralmente apresentando frequência relativamente baixa em relação aos demais componentes do microfitoplâncton. No Canal de Beagle, Candel et al. (2009) registraram B. simplex em amostras interpretadas sob condições de ambiente nerítico interno a marinho marginal, com salinidade baixa a moderada, temperatura da água de temperada a fria e rica em nutrientes.

\section{Brigantedinium spp.}

(Figura 3. C)

Descrição: cistos esféricos a subesféricos; parede lisa sem tabulação e de cor marrom a castanha; arqueopilo intercalar.

Dimensões (2 espécimes): diâmetro maior $25 \mu \mathrm{m}$. Observações: nos dois espécimes registrados, o arqueopilo é de difícil identificação; a má preservação impediu uma designação específica para os espécimes registrados.

Representante moderno: Protoperidinium Bergh 1881.

Observações: espécie cosmopolita, com distribuição em ambientes estuarinos, costeiros e oceânicos modernos, de distintas zonas climáticas (Wall et al., 1977; Rochon et al., 1999; de Vernal et al., 2001; Marret \& Zonneveld, 2003; Zonneveld et al., 2013; Price et al., 2016); considerada oportunista, sem fatores físicoquímicos limitantes expressivos (Rochon et al., 1999; de Vernal et al., 2001; Marret \& Zonneveld, 2003; Zonneveld et al., 2013).
Abundante no litoral leste do Japão devido à grande produtividade primária da região (Matsuoka, 1992). Espécimes de Brigantedinium foram registrados em amostras (aflorantes e testemunhos) das margens do Canal de Beagle (sul da América do Sul), interpretadas como de ambiente nerítico interno a externo (Grill et al., 2002; Borromei \& Quattrocchio, 2007) e ambiente nerítico interno a marinho marginal (Candel et al., 2009, 2011), com salinidade baixa a variável, temperatura da água de temperada a fria, concentração elevada de nutriente devido ao aporte d'água doce oriunda do derretimento das geleiras. Oliveira (2011) registrou o gênero em amostras da Bacia de Campos, Brasil, relacionado a condições ambientais transicionais, entre nerítico externo a oceânico. $\mathrm{Na}$ mesma bacia, Souza (2012) documentou o gênero Brigantedinium em assembleia de cistos de dinoflagelados típicas de ambiente marinho de alta produtividade.

Gênero Selenopemphix Benedek 1972 emend. Head 1993

Selenopemphix nephroides Benedek 1972 emend. Benedek \& Sarjeant 1981

(Figura 3. D)

Descrição: cisto peridinioide de formato ovoide em vista polar, compressão apical e antapical; autofragma de cor marrom, de superfície lisa; epicisto cônico, com contorno ligeiramente côncavo na secção dorsoventral, suportando uma saliência apical larga; epicisto cônico, com extremidade posterior truncada e sem chifres antapicais; paracíngulo estreito, bem definido por entalhe profundo; sulco largo e curto, bem indicado pela indentação do autofragma; arqueopilo grande, intercalar (2a), deslocado lateralmente à esquerda do eixo longitudinal.

Dimensões (2 espécimes): diâmetro maior 55 $\mu \mathrm{m}, 59 \mu \mathrm{m}$.

Representante moderno: Protoperidinium subinerme (Paulsen 1904) Loeblich 1970.

Observações: espécie restrita a áreas costeiras das zonas equatorial e temperada; porém, pode constituir parte proeminente das associações de mar aberto, especialmente nas proximidades da frente subtropical do Hemisfério Sul, em áreas oceânicas influenciadas pela pluma de sedimentos do Rio Amazonas no Atlântico Equatorial e porção central do Atlântico Norte (Marret \& Zonneveld, 2003; Zonneveld et al., 2013). Frequentemente registrada próxima das 
células de ressurgência do noroeste e sudoeste da África, comum nos mares Mediterrâneo, Meridional da China, de Okhotsk (noroeste do Pacífico) e de Bering (Pacífico Norte). Apresenta amplos parâmetros ambientais, temperatura d'água $-0,8^{\circ}$ a $29,8^{\circ} \mathrm{C}$ e salinidade $27,6 \%$ a $39,4 \%$, é heterotrófica, correlacionada com alto influxo de carbono orgânico e sílica biogênica (Marret \& Zonneveld, 2003; Zonneveld et al., 2013), também encontrada em áreas polares (Mudie \& Rochon, 2001; Radi et al. 2001). S. nephroides foi recuperada em depósitos da costa norte do Canal de Beagle, interpretada como de ambiente nerítico interno a externo, com salinidade baixa a variável, temperatura d'água de temperada a fria, com alta concentração de nutriente devido ao aporte d'água doce de derretimento das geleiras (Grill et al., 2002; Borromei \& Quattrocchio, 2007; Candel et al., 2009, 2011). No Brasil, a espécie foi encontrada em seções da Bacia de Campos, relacionadas a condições ambientais transicionais de nerítico externo a oceânico (Oliveira, 2011); Souza (2012) identificou as espécies em associações de cistos representativas de ambiente marinho de alta produtividade.

\section{Selenopemphix quanta Bradford 1975 emend. Matsuoka 1985 \\ (Figura 3. E)}

Descrição: cisto próximo-condensado com corpo subesférico, compressão apical e antapical, ornamentado por inúmeros processos; processos sólidos, com terminações afiadas ou sem corte, ocorrendo ao longo das margens singulares e em filas no epicisto e hipocisto; arqueopilo intercalar (2a), alongado, com ângulos arredondados.

Dimensões (1 espécime): diâmetro maior $60 \mu \mathrm{m}$; comprimento dos processos variando de 8 a $10 \mu \mathrm{m}$.

Representante moderno: Protoperidinium conicum (Gran 1900) Balech 1974.

Observações: espécie cosmopolita, de zonas costeiras, com distribuição delimitada pelos sistemas frontal Polar e Equatorial, porém pode ser registrada em águas oceânicas (Marret \& Zonneveld, 2003; Zonneveld et al., 2013). S. quanta é indicadora de enriquecimento de nutriente e alta produtividade das áreas costeiras (Pospelova et al., 2002, 2005), com condições preferenciais de temperatura $\left(8^{\circ}\right.$ a $\left.14^{\circ} \mathrm{C}\right)$ e salinidade (23\%o a $31 \%$ ), presente desde a zona polar do Norte à zona temperada do Sul (Rochon et al., 1999; de Vernal et al., 2001; Marret \& Zonneveld, 2003; Zonneveld et al., 2013; de Vernal et al., 2013). Apesar de ter condições preferenciais para sua proliferação, é um táxon resiliente, pois tolera uma ampla variação nos parâmetros ambientais, temperatura $\left(-2,1^{\circ}\right.$ a $29,8^{\circ}$ C) e salinidade $(16,8 \%$ a $39,2 \%$ ), com maior abundância relativa em regiões mesotróficas a eutróficas, onde as águas de fundo são anóxicas a óxicas (Marret \& Zonneveld, 2003; Zonneveld et al., 2013). No estuário de Bahía Blanca, Argentina, a forma móvel de $S$. quanta ( $P$. conicum) foi identificada em amostras de plâncton coletadas no Porto Cuatreros (Borel et al., 2006). A espécie foi registrada em amostras d'água do mar da plataforma continental da Província de Buenos Aires (Vilanova et al., 2008). Na área do Canal de Beagle, Candel et al. (2009, 2011) caracterizaram os depósitos em que o táxon foi identificado como de ambiente nerítico interno a marinho marginal, com salinidade de baixa a moderada, temperatura d'água de temperada a fria e rica em nutrientes. No Brasil, o táxon foi recuperado em seções da Bacia de Campos, relacionadas a condições ambientais transicional de nerítico externo a oceânico (Oliveira, 2011) e de ambiente marinho de alta produtividade (Souza, 2012).

\section{Gênero Lejeunecysta Artzner \& Dörhöfer 1978} emend. Letin \& Williams 1976

\section{Lejeunecysta spp.}

(Fig 3. F-H)

Descrição: cisto peridinioide, compressão dorso ventral; comprimento do epicisto e hipocisto aproximadamente igual; epicisto de forma cônica, com os lados retos; hipocisto com formato trapezoidal, com lados levemente côncavos; dois chifres antapicais curtos e um chifre apical curto arredondado; paratabulação indicada a partir do arqueopilo e do paracíngulo; paracíngulo marcado por uma depressão rasa; arqueopilo (2a).

Dimensões (3 espécimes): comprimento $39 \mu \mathrm{m}$, $60 \mu \mathrm{m}$ e $89 \mu \mathrm{m}$.

Observações: a má preservação impediu uma designação específica para os espécimes registrados.

Representante moderno: Protoperidinium Bergh 1881.

Observações: o gênero é identificado em sedimentos estuarinos modernos (Price et al., 2016). 
Conforme de Vernal et al. (2013), Lejeunecysta é indicativo de fácies nerítica, tolerante à variação de salinidade, entre 20\% a 35\%o, reconhecido nas zonas climáticas tropical a subpolar. Vilanova et al. (2008) registraram este táxon em sedimentos do Holoceno da plataforma continental da Província de Buenos Aires, interpretados como transicional costeiro a nerítico.

Subclasse PERIDINIPHYCIDAE Fensome et al. 1993

Ordem GONYAULACALES Taylor 1980

Subordem GONYAULACINEAE (autonímia)

Família GONYAULACACEAE Lindemann 1928

Subfamília CRIBROPERIDINIOIDEAE Fensome et al. 1993

Gênero Operculodinium Wall 1967 emend. Matsuola et al. 1997

Operculodinium centrocarpum (Deflandre \& Cookson 1955) Wall 1967

(Fig 3. I)

Descrição: cisto próximo-condensado, corpo central esférico, parede com superfície microreticular, espessada na base dos processos; processos atabulares com eixo sólido, de espessura fina e comprimento variável (entre $1 / 5$ e 1/4 do diâmetro do corpo central) e extremidade capitada; paracíngulo e parassulco indistintos; arqueopilo pré-cingular (3"); opérculo livre.

Dimensões (em 4 espécimes): diâmetro do corpo central 38 a $40 \mu \mathrm{m}$, comprimento dos processos 8,5 a $12 \mu \mathrm{m}$.

Representante moderno: Protoceratium reticulatum (Clararéde \& Lachmann 1859) Bütschli 1885.

Observações: presente em fácies sedimentares estuarina a oceânica de baixas a altas latitudes (Wall et al., 1977; Harland, 1983; Edwards \& Andrle, 1992; Rochon et al., 1999; Marret \& Zonneveld, 2003; Zonneveld et al., 2013; de Vernal et al., 2013; Price, 2016). Apresenta ampla distribuição por distintos parâmetros ambientais, temperatura da d'água $-2,1^{\circ}$ a $29,8^{\circ}$ C e salinidade 9,8\% a 39,4\% (Marret \& Zonneveld, 2003; Zonneveld et al., 2013). Espécie considerada cosmopolita (Wall et al., 1977; Marret \& Zonneveld, 2003; Zonneveld et al., 2013; de Vernal et al., 2013), porém não é registrada em águas permanentemente cobertas por gelo (Mudie, 1992). O táxon foi recuperado em sedimentos modernos e do Holoceno da plataforma argentina (Wall et al., 1977; Grill \& Guerstein, 1995; Grill \& Quattrocchio, 1996;
Gómez et al., 2005; Borel et al., 2006; Borel \& Gómez, 2006; Vilanova et al., 2008), em sedimentos do Holoceno do Canal de Beagle (Borromei \& Quattrocchio, 2001, 2007; Grill et al., 2002; Candel et al., 2009, 2012). No sul do Brasil, a espécie tem sido identificada em sedimentos do Holoceno da planície costeira e plataforma continental do Rio Grande do Sul e Santa Catarina (Lorscheitter \& Romero, 1985; Cordeiro \& Lorscheitter, 1994; Lorscheitter \& Dillenburg, 1998; Medeanic et al., 2000, 2009; Meyer et al., 2005ab, Macedo et al., 2007; Kuhn et al., 2017), interpretados como de ambiente lagunar, sendo utilizado como descritores das ingressões marinhas do Holoceno.

Subfamília GONYAULACOIDEAE (autonímia)

Gênero Spiniferites Mantel 1850 emend. Sarjeant 1970

Spiniferites spp.

(Fig 3. J-L)

Descrição: cisto próximo-condensado a condensado; corpo central esférico a oval; parede acavada, superfície lisa ou microgranular; processos sólidos ou ocos, simples, ramificado ou ramificado de forma complexa, podem ser gonais ou suturais; arqueopilo pré-cingular (3"); opérculo livre.

Dimensões (em 3 espécimes): tamanho do corpo central 49,5 a $56 \mu \mathrm{m}$, comprimento dos processos variando de 10 a $15 \mu \mathrm{m}$.

Observações: quando ocorre, a ligação entre os processos se dá por membranas que os unem a partir de sua base; espécie representada por diversos espécimes ao longo da seção, geralmente mal preservados e/ou associados à matéria orgânica amorfa, o que impediu uma designação específica.

Representante moderno: Gonyaulax Diesing 1866.

Observações: Spiniferites é registrado numa grande gama de ambientes, desde nerítico interno até oceano aberto, amplamente distribuído em todas as zonas climáticas, com tolerância às variações físico-químicas d'água (nutriente, salinidade, luminosidade), distribuído em áreas com distintos parâmetros ambientais (Wall et al., 1977; Harland, 1983; de Vernal et al., 2001; Zonneveld et al., 2013). Espécies do gênero têm sido identificadas em depósitos do Holoceno da planície costeira e plataforma continental Sul do Brasil, interpretadas como representativas de 
ambientes lagunares, também utilizadas como um dos descritores das ingressões marinhas do Holoceno (Lorscheitter \& Romero, 1985;

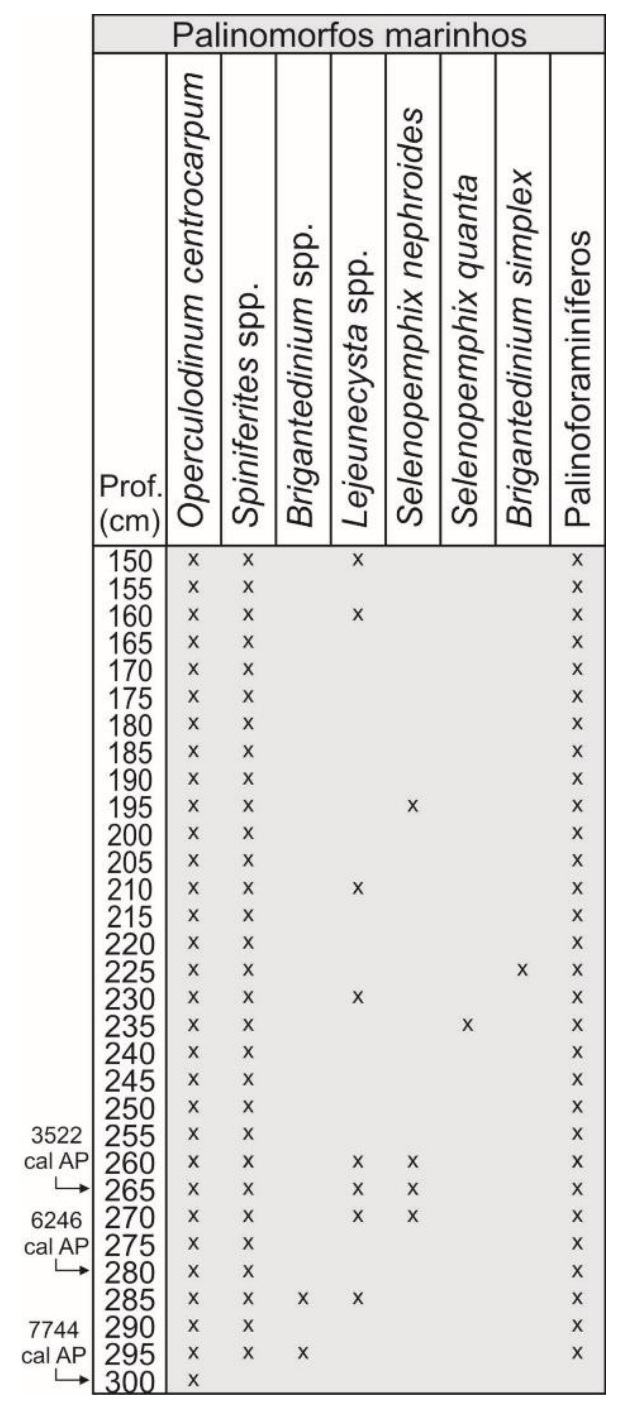

\section{DISCUSSÃO DOS RESULTADOS}

\section{Considerações paleoambientais}

Os táxons de cistos de dinoflagelados $B$. simplex, Brigantedinium spp, Lejeunecysta spp., $S$. nephroides, S. quanta, O. centrocarpum e Spiniferites spp. podem ser relacionados diretamente a espécies viventes nos mares e oceanos modernos; como resultado, os parâmetros sobre distribuição (zonas climáticas), ambientes e salinidade são compiladas com base na literatura (Figura 5).

Palinoforaminíferos foram registrados nos mesmos níveis das assembleias de cistos de dinoflagelados (Figura 3. M-O, Figura 4). Palinoforaminíferos são relacionados a foraminíferos bentônicos (de Vernal \& Giroux, 1991; de Vernal 1992, Mudie et al., 2011; Ní Fhlaithearta et al., 2013).

Com base na distribuição biogeográfica dos
Cordeiro \& Lorscheitter, 1994; Lorscheitter \& Dillenburg, 1998; Medeanic et al., 2000, 2009; Meyer et al., 2005a).
Figura 4. Distribuição estratigráfica dos cistos de dinoflagelados e palinoforaminíferos no poço PSC-03, Holoceno da Planície Costeira de Santa Catarina. 


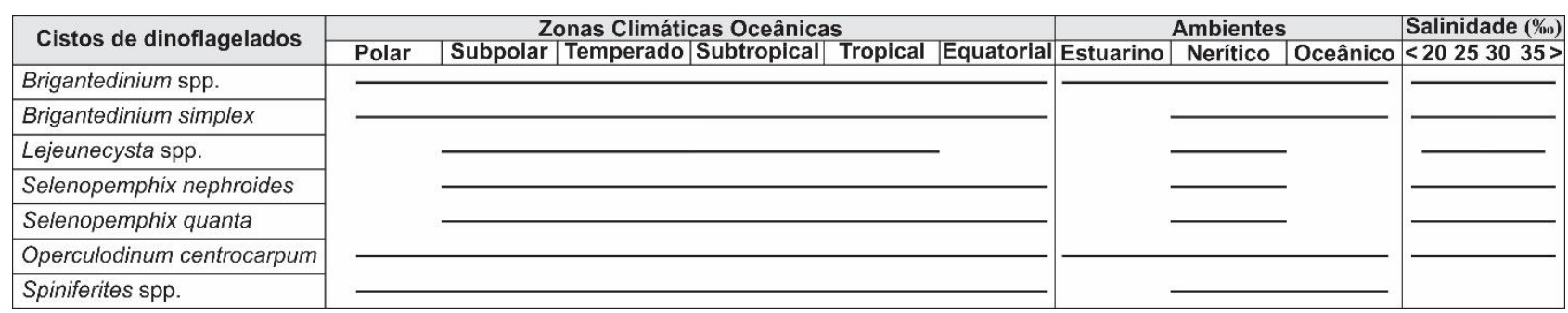

Figura 5. Distribuição de determinadas espécies de cistos de dinoflagelados nos sedimentos superficiais nos mares modernos e suas respectivas indicações em termos de zonas climáticas, ambiente e salinidade (compilado de Wall et al., 1977; Marret \& Zonneveld, 2003; de Vernal et al, 2013; Zonneveld et al., 2013).

constituem excelentes marcadores ambientais de influência ou conexão marinha com o sítio deposicional (Batten, 1996; de Vernal, 2009; Mudie et al., 2011). A alta frequência de grãos de pólen, esporos e fungos (Tabela 3) revela grande contribuição continental.

A baixa diversidade das associações de cistos de dinoflagelados indica condições restritas e es- tressantes, tais como grandes variações na salinidade (Figura 5) (Wall et al., 1977; Gorin \& Steffen, 1991; Tyson, 1995; Prauss, 2000). A ocor-rência de cistos peridinioides associados aos gonyaulacoides sugere que a área do sítio deposi-cional esteve sob influência de águas marinhas costeiras com grande aporte de nutrientes de origem continental (Wall et al., 1977; Dale, 1996).

\section{O REGISTRO DE CISTOS DE DINOFLAGELADOS EM SEDIMENTOS HOLOCENOS DA ZONA COSTEIRA SUL DO BRASIL}

Nos últimos anos diversos estudos palinológicos foram desenvolvidos na zona costeira do sul do Brasil (RS e SC) (e.g. Lorscheitter \& Romero, 1985; Cordeiro \& Lorscheitter, 1994; Neves, 1998; Lorscheitter \& Dillenburg, 1998; Behling \& Negrelle, 2001; Medeanic et al., 2000, 2009; Meyer et al., 2005ab; Macedo et al., 2007; Cancelli, 2012; Kuhn et al., 2017). O principal objetivo da maioria desses estudos foi a identificação de grãos de pólen e esporos de plantas continentais para a avaliação das mudanças paleovegetacionais e paleoclimáticas ocorridas na zona costeira e suas relações com as variações do nível relativo do mar durante o Holoceno.

Associados aos esporomorfos (grãos de pólen e esporos), em alguns desses trabalhos, foram registrados cistos de dinoflagelados, acritarcos, zigósporos e cenóbios de algas verdes. A transgressão marinha do Holoceno médio (7000 5000 cal AP) foi identificada a partir do reconhecimento de gêneros de cistos de dinoflagelados (Operculodinium e Spiniferites), associados ou não a outros palinomorfos marinhos (e.g. acritarcos e palinoforaminíferos).

Nos trabalhos citados, os cistos de dinoflagelados são representados por apenas dois gêneros; contudo, dinoflagelados, diatomáceas, cianofíceas e outras algas flageladas constituem a maior parte do fitoplâncton das águas costeiras modernas (Dale, 2009). Além da baixa diversidade de gêneros identificados até então, a representatividade quantitativa dos cistos de dinoflagelados em relação à assembleia de palinomorfos também é bastante reduzida, não ultrapassando valores de 5\% da assembleia palinológica (Neves, 1998; Lorscheitter \& Dillenburg, 1998; Medeanic et al., 2009; Meyer et al., 2005ab; Macedo et al., 2007; Kuhn et al., 2017).

$\mathrm{Na}$ análise palinológica desenvolvida em um poço perfurado em ambiente marinho de águas profundas na porção média do Cone do Rio Grande, extremo sul do Brasil, Lorscheitter \& Romero (1985) registraram amostras nas quais cistos de dinoflagelados constituem até $99,8 \%$ da associação palinológicas. Operculodinium centrocarpum e Spiniferites mirabilis foram identificados, e a taxonomia dos demais espécimes ficou em aberto sob a designação "cistos de dinoflagelados indeterminados". Ao longo das quatro fases ecológicas identificadas no poço, os cistos de dinoflagelados mostraram variações em frequência; na primeira fase, $O$. centrocarpum e $S$. mirabilis constituíram $\sim 10 \%$ de frequência da assembleia, em proporções semelhantes entre si, e aqueles indeterminados frequência $<10 \%$; durante a segunda fase, os cistos de dinoflagelados atingiram $\sim 65 \%$ da assembleia, com O. centrocarpum (60\%) prevalecendo sobre $S$. mirabilis (5\%), e cistos de dinoflagelados indeterminados com $11,8 \%$; na terceira fase, ocorrem decréscimo na frequência de $O$. centrocarpum e $S$. mirabilis $(\sim 15 \%)$, porém há uma inversão entre a frequência entre as espécies $S$. mirabilis 
$(\sim 12 \%)$ e O. centrocarpum ( $3 \%)$, e aqueles indeterminados $(\sim 5 \%)$; na última fase, a soma de O. centrocarpum, S. mirabilis e cistos de dinoflagelados indeterminados atingem 99,8\%, sendo $O$. centrocarpum a espécie dominante.

A contribuição de Lorscheitter \& Romero (1985) mostra grande participação de táxons marinhos, o que está diretamente relacionado à procedência da amostragem, circunscrita à área com cobertura do mar durante no intervalo entre o final do Pleistoceno e início do Holoceno.

Por outro lado, a baixa recuperação de espécies de cistos de dinoflagelados em depósitos do Holoceno da zona costeira sul do Brasil pode ser resultado de outros fatores. Geralmente, a maior atenção é empregada na identificação detalhada dos esporomorfos a fim de obter resultados sobre a dinâmica da vegetação de cada área; palinomorfos de natureza marinha são taxomicamente subestimados.

Eventos pós-deposicionais podem afetar a preservação dos cistos de dinoflagelados incorporados aos depósitos sedimentares. Estudos experimentais têm demonstrado que cistos de dinoflagelados são mais suscetíveis à degradação nas etapas em que estejam expostos à oxidação, tanto em eventos pós-deposicionais, bem como em etapas do processamento palinológico de sedimentos e rochas sedimentares (Prauss, 2000; Hopkins \& McCarthy, 2002; Zonneveld et al., 2008).

Dale (1976) demonstrou que algumas etapas do processamento, com o uso de ácidos fortes e aquecidos, a acetólise, ou exposição à oxidação com $\mathrm{KOH}$, têm efeitos cruciais para determinadas espécies de cistos de dinoflagelados, podendo eliminá-las, caso estejam presentes nos materiais. Tais procedimentos não foram evitados na maior parte dos trabalhos desenvolvidos na zona costeira do sul do Brasil (e.g., Lorscheitter \& Romero, 1985; Cordeiro \& Lorscheitter, 1994; Neves, 1998; Lorscheitter \& Dillenburg, 1998; Medeanic et al., 2000, 2009; Meyer et al., 2005b; Macedo et al., 2007; Kuhn et al., 2017). Nestes, a metodologia padrão adotada é a de recuperação palinológica para sedimentos turfosos, com vistas à análise sobre a paleovegetação representada e reconstituição dos paleoclimas (Faegri \& Iversen, 1975; Ybert et al., 1992).

Desde a publicação de Dale (1976), importantes avanços foram realizados no conhecimento sobre o potencial de preservação de palinomorfos marinhos e estuarinos e os métodos de processamento mais adequado para sua recuperação (Head, 1996; Zonneveld et al., 1997, 2008; Oliveira et al., 2004; Mudie et al., 2011).

Em Zonneveld et al. (2001), táxons de dinoflagelados foram classificados de acordo com sua sensibilidade em relação à variação de oxigênio no sedimento de fundo. Nesse aspecto, dinoflagelados protoperidinioides são os mais sensíveis à degradação seletiva (Tabela 4). Estes elementos são heterotróficos, alimentam-se preferencialmente de diatomáceas e são excelentes descritores da paleoprodutividade do corpo d'água (Zonneveld et al.,2001; Mudie et al., 2011).

Tabela 4. Espécies de cistos de dinoflagelados agrupadas em relação à sua sensibilidade ao oxigênio disponível no sedimento de fundo (modificado de Zonneveld et al., 2001).

\begin{tabular}{ll}
\hline $\begin{array}{l}\text { Extremamente } \\
\text { sensíveis }\end{array}$ & Protoperidinioides (e.g. Brigantidinium spp.) e espécies de Echinidinium \\
\hdashline $\begin{array}{l}\text { Moderadamente } \\
\text { sensíveis }\end{array}$ & $\begin{array}{l}\text { Lingulodinium machaerophorum, Protceratium reticulatum, Pyxidinopsis reticulatum, espécies } \\
\text { de Spiniferites (incluindo S. bentori, S. mirabilis, S. pachyderma e S. ramosus) }\end{array}$ \\
\hline & $\begin{array}{l}\text { Nematosphaeropsis labyrinthus, Impagidinium aculeatum, I. paradoxum, I. patulum, I. plicatum, } \\
\text { Resistentes }\end{array}$ \\
$\begin{array}{l}\text { I. sphaericum, Operculodinium israelianum, Pentapharsodinium dalei e Polysphaeridium } \\
\text { zoharyi }\end{array}$ \\
\hline
\end{tabular}

Conforme Mudie et al. (2011), embora a composição química da parede de cistos de dinoflagelados e acritarcos seja similar a dos esporomorfos, não é constituída de esporopolenina, composto muito resistente à oxidação. Os biopolímeros que compõem a parede dos cistos de dinoflagelados e ficomas das clorofíceas são mais lábeis e podem ser afetados por influência oxidativas (de Vernal \& Marret,
2007). Segundo Prauss (2000), durante os eventos de variação do nível do mar, as associações depositadas na interface águasedimento são expostas a vários processos dinâmicos, tais como erosão, remobilização e mistura de diferentes massas d'água, que afetam as associações do microplâncton na coluna d'água e no sedimento, em escalas local e regional. 
Devido à intensa dinâmica dos processos sedimentares, as associações palinológicas incorporadas aos depósitos sedimentares podem sofrer profundas alterações pós-deposicionais, muitas vezes refletidas na má preservação dos palinomorfos ou em insuficiência amostral (esterilidade e/ou baixa recuperação), como observado em materiais descritos da planície costeira e plataforma continental argentina (Vilanova et al., 2006; Vilanova et al., 2008; Prieto, 2016).

Como resultado da análise desses dados da literatura, verifica-se que diferentes parâmetros podem afetar a natureza das associações palinológicas recuperadas em depósitos sedimentares quaternários costeiros, sejam naturais ou induzidos por força do tipo de processamento laboratorial. No caso do material aqui apresentado, a maior quantidade de espécies registradas de cistos de dinoflagelados está diretamente relacionada ao tratamento não oxidativo empregado, bem como ao detalhamento taxonômico adotado, na tentativa de melhor assignação específica.

\section{CONCLUSÕES}

A quase totalidade dos estudos palinológicos desenvolvidos nos depósitos costeiros do sul do Brasil é concentrada na análise dos esporomorfos. Neste trabalho foi demonstrado o potencial dos cistos de dinoflagelados na interpretação paleoambiental em depósitos costeiros do Holoceno de Santa Catarina, baseando em amostras de testemunho (poço PSC-03). Estes grupos de microfósseis de parede orgânica foram recuperados dos sedimentos turfosos a partir de processamento laboratorial particular, evitando-se sua exposição à oxidação, resultando em um maior número de táxons descritos.

A comparação dos táxons de dinoflagelados do testemunho e seus análogos modernos permitiu inferir condições de deposição plataformais para grande parte do intervalo estudado. A presença de palinoforaminíferos corrobora a ideia, bem como a ação direta de águas marinhas costeiras sobre a área do sítio deposicional durante parte de seu período de preenchimento sedimentar.

Brigantedinium spp., Brigantedinium simplex, Lejeunecysta spp., Selenopemphix nephroides e Selenopemphix quanta constituem táxons de dinoflagelados registrados pela primeira vez em sedimentos do Holoceno da planície costeira brasileira. Essas ocorrências no material estudado e sua ausência em trabalhos anteriores devem estar relacionadas, se não à natureza do sítio deposicional, aos métodos de recuperação palinológica empre-gados em cada laboratório, os quais, em sua maioria, são relativos a tratamentos oxidativos, tais como a acetólise, exposição à oxidação (eg. $\mathrm{KOH})$, muitas vezes como processos catalizadores nas reações de eliminação da matéria orgânica distinta daquela dos esporo-morfos. Tais procedimentos são amplamente utilizados em depósitos turfosos para fins de análise da paleovegetação e respectivos paleoclimas, para os quais os esporos e grãos de pólen constituem ferramenta micropaleon-tológica singular. Contudo, para depósitos da interface continente/oceano, o tipo de recuperação dos palinomorfos deve contemplar a possibilidade do registro de outros palino-morfos, tais como os cistos de dinoflagelados, palinoforaminíferos. Dessa forma, recomenda-se a introdução de métodos alternativos, muitos dos quais já conhecidos, para depósitos mais antigos e/ou de outras regiões do mundo, mas não aplicados para a planície costeira do sul do Brasil, bem como a designação taxonômica detalhada dos cistos de dinoflagelados e sua comparação com os análogos modernos.

\section{AGRADECIMENTOS}

Os autores agradecem à Coordenação de Aperfeiçoamento de Pessoal de Nível Superior (CAPES) pelo período de concessão de bolsa de doutorado de WGS (2013-2015), ao Conselho Nacional de Desenvolvimento Científico e Tecnológico (CNPq) pela bolsa de produtividade em pesquisa de PAS (proc. 310727/2014-6), à Fundação de Amparo à Pesquisa do Estado do Rio Grande do Sul (FAPERGS proc. 1012119) por recursos financeiros por meio de projeto de pesquisa e ao Programa de Capacitação dos Servidores do Instituto Federal de Educação, Ciência e Tecnologia do Rio Grande do Sul (IFRS proc. 233670022072015-50). Esta contribuição é parte da Tese de Doutorado do primeiro autor, desenvolvida no Programa de Pós-Graduação em Geociências da UFRGS. Os autores também agradecem ao revisor do manuscrito pela leitura crítica e sugestões. 


\section{REFERÊNCIAS}

AKSELMAN, R. Quistes planctonicos de dinoficeas en areas de plataforma del atlantico sudoccidental, I, reporte taxonomico de la Fasmilia Peridiniaceae Ehrenber. Boletim do Instituto Oceanográfico de São Paulo, v. 35, n. 1, p. 17-32, 1987.

AMARAL, P.G.C.; GIANNINI, P.C.F.; SYLVESTRE, F.; PESSENDA, L.C.R. Paleoenvironmental reconstruction of a Late Quaternary lagoon system in southern Brazil (Jaguaruna region, Santa Catarina state) based on multi-proxy analysis. Journal of Quaternary Science, v. 27, n.2, p. 181-191, 2012.

AMARAL, P.G.C.; LEDRU, M.; BRANCO, F.R.; GIANNINI, P.C.F. Late Holocene development of a mangrove ecosystem in southeastern Brazil (Itanhaém, state of São Paulo). Palaeogeography, Palaeoclimatology, Palaeoecology, v. 241, n. 3-4, p. 608-620, 2006.

BATTEN, D.J. Palynofacies and palaeoenvironmental interpretation. In: JANSONIUS, J.; MCGREGOR, D.C. (Editors). Palynology: principles and applications, v.3. American Association of Stratigraphic Palynologists Foundation, p. 29-50, 1996.

BEHLING, H. First report on new evidence for the occurrence of Podocarpus and possible human presence at the mouth of the Amazon during the Late-glacial. Vegetation History and Archaeobotany, v. 5, n. 3, p. 241-246, 1996.

BEHLING, H. \& NEGRELLE, R.R.B. Tropical rain forest and climate dynamics of the atlantic lowland, Southern Brazil, during the Late Quaternary. Quaternary Research v. 56, n. 3, p. 383-389, 2001.

BOREL, C.M. \& GÓMEZ, E.A. Palinología del Holoceno del Canal del Medio, estuario de Bahía Blanca (Buenos Aires, Argentina). Ameghiniana, v. 43, n. 2, p. 399-412, 2006.

BOREL, C.M.; CERVELLINI, P.M.; GUERSTEIN, G.R. Qustes de dinoflagelados de sedimentos holocenos y dinoflagelados modernos del estuário de Bahía Blanca, Argentina. Geoacta, v. 31, p. 23-31, 2006.

BORROMEI, A.M. \& QUATTROCCHIO, M. Palynological study of Holocene marine sediments from Bahía Lapataia, Beagle Channel, Tierra del Fuego, Argentina. Revista Española de Micropaleontología, v. 33, n. 1, p. 61-70, 2001.

BORROMEI, A.M. \& QUATTROCCHIO, M. Holocene sealevel change and marine palynology of the Beagle Channel, southern Tierra del Fuego, Argentina. Ameghiniana, v. 44, n. 1, p.161-171, 2007.

CANCELLI, R.R. Evolução paleoambiental da Planície Costeira sul-catarinense (Lagoa do Sombrio) durante o Holoceno, com base em dados palinológicos. Porto Alegre, 2012. 159 p. Tese (Doutorado em Geociências) - Instituto de Geociências, Universidade Federal do Rio Grande do Sul.

CANDEL, M.S.; BORROMEI, A.M.; MARTÍNEZ, M.A.; GORDILLO, S.; QUATTROCCHIO, M.; RABASSA, J. Middle-Late Holocene palynology and marine mollusks from Archipiélago Cormoranes area, Beagle Channel, southern Tierra del Fuego, Argentina. Palaeogeography, Palaeoclimatology, Palaeoecology, v. 273, n. 1-2, p.111-122, 2009.

CANDEL, M.S.; RADI, T.; de VERNAL, A.; BUJALESKY, G. Distribution of dinoflagellate cysts and other aquatic palynomorphs in surface sediments from the Beagle Channel, Southern Argentina, Marine Micropaleontology, v. 96-97, p. 1-12, 2012.

CANDEL, M.S.; BORROMEI, A.M.; MARTÍNEZ, M.A.; BUJALESKY, G. Palynofacies analysis of surface sediments from the Beagle Channel and its application as modern analogues for Holocene records of Tierra del Fuego, Argentina. Palynology, v. 37, n. 1, p. 62-76, 2013.

CANDEL, M.S.; MARTÍNEZ, M.A.; BORROMEI, A.M. Palinología y palinofacies de una secuencia marina del Holoceno medio-tardío: Albufera Lanushuaia, Canal Beagle, Tierra del Fuego, Argentina. Revista Brasileira de Paleontologia, v. 14, n. 3, p. 297-310, 2011.

CORDEIRO, S.H. \& LORSCHEITTER, M.L. Palynology of
Lagoa dos Patos sediments, Rio Grande do Sul, Brazil. Journal of Paleoliminology, v. 10, n. 1, p. 35-42, 1994.

CORRÊA, I.C.S. \& VILLWOCK, J.A. Continental Shelf and Coastal Plain Sediments of the EDITORESSoutheast and South Coast of Brazil. In: CORRÊA, I.C.S. \& MARTINS, L.R. (Editores). Exploratory text of Atlas: Morphology and Sedimentology of the Southwest Atlantic Coastal Zone and Continental Shelf from Cabo Frio (Brazil) to Peninsula Valdés (Argentina). CECO. p. 41-54, 1996.

CORRÊA, I.C.S; MARTINS, L.R.; KETZER, J.M.M.; ELIAS, A.R.D.; MARTINS, R. Evolução Sedimentológica e Paleogeográfica da Plataforma Continental Sul e Sudeste do Brasil. Notas Técnicas, n. 9, p. 51-61, 1996.

DALE, B. Cyst formation, sedimentation and preservation: factors affecting dinoflagellate assemblages in recent sediments from Trondheimsfjord, Norway. Review of Palaeobotany and Palynology, v. 22, n. 1, p. 39-60, 1976.

DALE, B. Dinoflagellate cyst ecology: modeling and geological applications. In: JANSONIUS, J. \& MCGREGOR, D.C. (Editores), Palynology: Principles and applications, v. 3. American Association of Stratigraphic Palynologists Foundation, p. 1249-1275, 1996.

DALE, B. Eutrophication signals in the sedimentary record of dinoflagellate cysts in coastal waters. Journal of Sea Research, v 61, n. 1, p. 103-113, 2009.

DE VERNAL, A. Marine palynology and its use for studying nearshore environments. IOP Conf. Series: Earth and Environmental Science, v. 5, n. 1, p. 1-13, 2009. Disponível em: http://iopscience.iop.org/article/10.1088/1755-1307/5/1/ 012002. Acessado em: 09out2016.

DE VERNAL, A. \& GIROUX, L. Distribution of organic walled microfossils in Recent sediments from the estuary and Gulf of St. Lawrence: some aspects of the organic matter fluxes. In: THERRIAULT, J.C. (Editor), The Gulf of St. Lawrence: small ocean or big estuary Canadian Special Publication of Fisheries and Aquatic Sciences, v. 113, p. 189-199, 1991.

DE VERNAL, A. \& MARRET, F. Organic-Walled Dinoflagellate Cysts: Tracers of Sea-Surface Conditions. In: HILLARIE-MARCEL, C. \& de VERNAL, A. (Editores), Developments in Marine Geology, Elsevier, v.1, p. 371-408, 2007. Disponível em: http://www.sciencedirect.com/science/ article/pii/S15725 48007010147. Acessado em: 27nov2014.

DE VERNAL, A; BILODEAU, G.; HILLAIRE-MARCEL, C.; KASSOU, N. Quantitative assessment of carbonate dissolution in marine sediments from foraminifer linings vs. shell ratios: Davis Strait, northwest North Atlantic. Geology, v. 20, n. 6, p. 527-530, 1992.

DE VERNAL, A.; HENRY, M.; MATTHIESSEN, J.; MUDIE, P.J.; ROCHON, A., BOESSENKOOL, K.P.; EYNAUD F.; GRØSFJELD, K.; GUIOT, J., HAMEL, D., HARLAND, R. HEAD, M.J.; KUNZ-PIRRUNG, M.; LEVAC, E.; LOUCHEUR, V.; PEYRON, O.; POSPELOVA, V.; RADI, T.; TURON, J.-L.; VORONINA, E. Dinoflagellate cyst assemblages as tracers of sea-surface conditions in the northern North Atlantic, Arctic and sub-Arctic seas: the new ' $n=677$ ' data base and its application for quantitative palaeoceanographic reconstruction. Journal of Quaternary Science, v. 16, n. 7, p. 681-698, 2001.

DE VERNAL, A.; ROCHON, A.; RADI T. DINOFLAGELLATES. In: ELIAS, S.A. (Editor), The Encyclopedia of Quaternary Science, Elsevier, .v. 2, p. 800-815, 2013.

EDWARDS, L.E. \& ANDRLE, V.A.S. Distribution of selected dinoflagellate cysts in modern marine sediments. In: HEAD M.J. \& WRENN J.H. (Editores), Neogene and quaternary dinoflagellate cysts and acritarchs, American Association of Stratigraphic Palynologists Foundation, p. 259-288, 1992.

FAEGRI, K.; IVERSEN, J. Textbook of pollen analysis. 3 rd. Edition, Hafner Press, 295p., 1975. 
FENSOME, R.A. \& WILLIAMS, G.L. The Lentin and Williams index of fossil dinoflagellates 2004 edition. American Association of Stratigraphic Palynologists, Contribution Series 42, p. 1-909, 2004.

GÓMEZ, E.A.; MARTÍNEZ, D.E.; BOREL, C.M.; GUERSTEIN, G.R. CUSMINSKY, G.C. Submarine evidence of Holocene sea level fluctuations in the Bahía Blanca estuary, Argentina. Journal of South American Earth Sciences, v. 20 n. 1-2, p. 139-155, 2005.

GORIN, G.E. \& STEFFEN, D. Organic facies as a tool for recording eustatic variations in marine fine-grained carbonatesexample of the Berriasian stratotype at Berrias (Ardèche, SE France). Palaeogeography, Palaeoclimatology, Palaeoecology, v. 85, n. 3-4, p. 303-320, 1991.

GRILL, S. \& GUERSTEIN, G.R. Estudio palinológico de sedimentos superficiales en el estuario de Bahía Blanca, provincia de Buenos Aires, Argentina. Polen, v. 7, p. 41-49, 1995.

GRILL, S. \& QUATTROCCHIO, M. Fluctuaciones eustáticas durante el Holoceno a partir del análisis de palinomorfos. Localidad: Grümbein. Sur de la provincia de Buenos Aires. Ameghiniana, v. 33, n. 4, p.435-442, 1996.

GRILL, S.; BORROMEI, A.M.; QUATTROCCHIO, M.; CORONATO, A.; BUJALESKY, G.; RABASSA, J Palynological and sedimentological analysis of Recent sediments from Río Varela, Beagle Channel, Tierra del Fuego, Argentina. Revista Española de Micropaleontología, v. 34, n. 2, p. 145-161, 2002.

HARLAND, R. Distribution maps of recent dinoflagellate cysts in bottom sediments from the North-Atlantic Ocean and adjacent seas. Palaeontology, v. 26, n. 2, p. 321-387, 1983

HEAD, M.J. Modern dinoflagellate cysts and their biological affinities. In: JANSONIUS, J.; MCGREGOR, D.C. (Editores). Palynology: principles and applications, v. 3. American Association of Stratigraphic Palynologists Foundation, p. 1197 1248,1996

HOGG, A.G.; HUA, Q.; BLACKWELL, P.G.; NIU, M.; BUCK, C.E.; GUILDERSON, T.P.; HEATON, T.J.; PALMER, J.G.; REIMER, P.J.; REIMER, R.W.; TURNEY, C.S.M.; ZIMMERMAN, S.R.H. SHCAL13 SOUTHERN HEMISPHERE CALIBRATION, 0-50,000 YEARS CAL BP. Radiocarbon, v. 55, n. 4, p.1889-1903, 2013.

HOPKINS, J.A. \& MCCARTHY, F. Post-Depositional Palynomorph Degradation in Quaternary Shelf Sediments: A Laboratory Experiment Studying the Effects of Progressive Oxidation. Palynology, v. 26, p.167-184, 2002.

HORN FILHO, N.O. Setorização da província costeira de Santa Catarina, em base aos aspectos geológicos, geomorfológicos e geográficos. Geosul, v. 18, n. 35, p. 71-98, 2003.

KOWSMANN, R.O.; COSTA, M.P.A.; VICALVI, M.A.; COUTINHO, M.G.N.; GAMBOA, S.A.P. Modelo de sedimentação holocênica na plataforma continental sul brasileira. PROJETO REMAC, n. 2, p. 7-26, 1977

KUHN, L.A.; SOUZA, P.A.; CANCELLI, R.R.; SILVA, W.G. \& MACEDO, R.B. 2017. Paleoenviromental evolution of the coastal plain of southern Brazil: palynological data from a Holocene core in Santa Catarina state. Anais da Academia Brasileira de Ciências, 89: 2581-2595. doi:10.1590/0001-3765201720160895.

LORENT, F.L.; PESSENDA, L.C.R.; OBOH-IKUENOBE, F.; BUSO JR, A.A.; COHEN, M.C.L.; MEYER, K.E.B.; GIANNINI, P.C.F.; de OLIVEIRA, P.E.; ROSSETTI, D.F.; FILHO, M.A.B.; FRANÇA, M.C.; CASTRO, D.F.; BENDASSOLLI, J.A.; MACARIO, K. Palynofacies and stable $\mathrm{C}$ and $\mathrm{N}$ isotopes of Holocene sediments from Lake Macuco (Linhares, Espírito Santo, southeastern Brazil): Depositional settings and palaeoenvironmental evolution. Palaeogeography, Palaeoclimatology, Palaeoecology, v. 415, n. 1, p. 69-82, 2014.

LORSCHEITTER, M.L. \& DILLENBURG, S.R. Holocene paleoenvironments of the northern coastal plain of Rio Grande do Sul, Brazil, reconstructed from palynology of Tramandaí lagoon sediments. Quaternary of South America and Antarctic Peninsula, v.11, n.1, p. 73-97, 1998.

LORSCHEITTER, M.L. \& ROMERO, E.J. Palynology of Quaternary sediments of the core T15, Rio Grande Cone, South Atlantic, Brazil. Quaternary of South America and Antarctic Peninsula, v. 3, n.1, p. 55-92, 1985.

MACEDO, R.B.; CANCELLI, R.R.; BAUERMANN, S.G.; BORDIGNON, S.A.L.; NEVES, P.C.P. Palinologia de níveis do Holoceno da Planície Costeira do Rio Grande do Sul (Localidade de Passinhos), Brasil. Gaea, v. 3, n.2, p. 68-74, 2007.

MARRET, F. \& ZONNEVELD, K.A.F. Atlas of modern organicwalled dinoflagellate cyst distribution. Review of Palaeobotany and Palynology, v. 125, n. 1-2, p. 1-200, 2003.

MARTIN, L.; SUGUIO, K.; FLEXOR, J.M. As flutuações do nível do mar durante o Quaternário superior e a evolução geológica de "deltas" brasileiros. Boletim IG-USP, Publicação Especial v.15, p.1-186, 1993.

MARTIN, L.; DOMINGUEZ, M.L.; BITTENCOURT, A.C.S.P. Fluctuating Holocene Sea Levels in Eastern and Southeastern Brazil: Evidence from Multiple Fossil and Geometric Indicators. Journal of Coastal Research, v. 19, n.1, p. 101-124, 2003.

MATSUOKA, K. Species diversity of modern dinoflagellate cysts in surface sediments around the Japanese islans. In: Head M.J. \& Wrenn J.H. (Editores), Neogene and quaternary dinoflagellate cysts and acritarchs, American Association of Stratigraphic Palynologists Foundation, p. 33-53, 1992.

MATTHIESSEN, J. Distribution Patterns of dinoflagellate cysts and other organic-walled microfossils in recent NorwegianGreenland sea sediments. Marine Micropaleontology, v. 24, n. 3-4, p. 307-334, 1995.

MATTHIESSEN, J.; de VERNAL, A.; HEAD, M.J.; OKOLODKOV, Y.B.; ZONNEVELD, K.A.F.; HARLAND, R. Modern organic-walled dinoflagellate cysts in Artic marine environments and their (paleo) environmental significance. Paläontologische Zeitschrift, v. 79, n. 1, p. 3-51, 2005.

MEDEANIC, S.; TOLDOJUNIOR E.E.; DILLENBURG, S.R. Palynological evidence of marine ingression in the lagoa dos Patos Laggoon during the late Holocene. Geociências, n. especial, p.141-145, 2000.

MEDEANIC, S.; TORGAN, L.C.; CLEROT, L.C.P.; SANTOS, C.B. Holocene marine transgression in the Coastal Plain of Rio Grande do Sul, Brazil: palynomorph and diatom evidence. Journal of Coastal Research, v. 25, n. 1, p. 224-233, 2009.

MEYER, K.E.B.; MENDONÇA FILHO, J.G.; ASHRAF, A.R.; SOUZA, P.A.; REICHHART, K. Análise de palinofácies em sedimentos holocênicos da Lagoa dos Quadros, Planície Costeira do Rio Grande do Sul, Brasil. Revista Brasileira de Paleontologia, v. 8, n. 1, p. 57-72, 2005a.

MEYER, K.E.B.; REICHHART, K.; ASHRAF, A.R.; MARQUES-TOIGO, M., MOSBRUGGER, V. Holocene Evolution of Itapeva lake, Rio Grande do Sul, Brazil: Palynomorphs and Corg, N, S Records. Journal of South American Earth Sciences, v.19, n. 2, p 181-192, 2005 b.

MUDIE, P.J. Circum-Arctic Quaternary and Neogene marine palynofloras: paleoecology and statistical analysis. In: HEAD M.J. \& WRENN J.H. (Editores), Neogene and quaternary dinoflagellate cysts and acritarchs, American Association of Stratigraphic Palynologists Foundation, p. 347-390, 1992.

MUDIE, P.J. \& HARLAND, R. Aquatic Quaternary. In: Jansonius, J. \& McGregor, D.C. (Editores), Palynology: Principles and applications, v. 2. American Association of Stratigraphic Palynologists Foundation, p. 843-878, 1996.

MUDIE, P.J.; ROCHON, A. Distribution of dinoflagellate cysts in the Canadian Arctic marine region. Journal of Quaternary Science, v. 16, n. 7, p. 603-620, 2001

MUDIE, P.J.; LEROY, S.A.G.; MARRET, F.; GERASIMENKO, N.P.; KHOLEIF, S.E.A.; SAPELKO, T.; FILIPOVAMARINOVA, M. 2011. Nonpollen palynomorphs: indicators of salinity and environmental change in the Caspian-Black SeaMediterranean corridor, in: Buynevich, I.V., Yanko-Hombach, 
V., Gilbert, A.S., Martin, R.E. (Editores.), Geology and Geoarchaeology of the Black Sea Region: Beyond the Flood Hypothesis: Geological Society of America Special Paper, v. 473, p. 89-115, 2011

NEVES, P.C.P. Palinologia de sedimentos quaternários no estado do Rio Grande do Sul, Brasil: Guaíba e Capão do Leão. Porto Alegre 1998. 513 p. Tese (Doutorado em Geociências) - Instituto de Geociências, Universidade Federal do Rio Grande do Sul.

NÍ FHLAITHEARTA, S.; ERNST, S.R.; NIEROP, K.G.J.; DE LANGE, G.J.; REICHART, G.-J. Molecular and isotopic composition of foraminiferal organic linings. Marine Micropaleontology, v. 102, p. 69-78, 2013

NORONHA, B.T. Alterações paleoambientais inferidas por associações de dinoflagelados e outros palinomorfos recuperados em um testemunho quaternário da Bacia de Campos. Porto Alegre, 2011. 91 p. Monografia (Bacharel em Ciências Biológicas) - Instituto de Biociências, Universidade Federal do Rio Grande do Sul.

OLIVEIRA, A.D.; MENDONÇA FILHO, J.G.; CARVALHO, M.A.; MENEZES, T.R.; LANA, C.C.; BRENNER, W.W. Novo método de preparação para aumentar a recuperação de dinoflagelados. Revista Brasileira de Paleontologia, v.7, n. 2, p. 169-175, 2004.

OLIVEIRA, A.D. Reconstrução paleoambiental com base nas assembleias de dinoflagelados presentes nos sedimentos do Holoceno e Pleistoceno do talude continental brasileiro da Bacia de Campos, RJ-Brasil. Rio de Janeiro, 2003. 198 p. Dissertação (Mestrado em Geociências) - Instituto de Geociências, Universidade Federal do Rio de Janeiro.

OLIVEIRA, A.D. Estudo integrado de palinofácies com cistos de dinoflagelados fósseis (dinocistos) de zona climática tropical em sedimentos quaternários de águas profundas da Bacia de Campos, RJ-Brasil. Rio de Janeiro, 2011. 257 p. Tese (Doutorado em Geociências) - Instituto de Geociências, Universidade Federal do Rio de Janeiro.

POSPELOVA, V.; CHMURA, G.L.; BOOTHMAN, W.S.; LATIMER. J.S. Dinoflagellate cyst records and human disturbance in two neighboring estuaries, New Bedford Harbor and Apponagansett Bay, Massachusetts (USA). The Science of the Total Environment, v. 298, n. 1-3, p.81-102, 2002.

POSPELOVA, V.; CHMURA, G.L.; BOOTHMAN, W.S.; LATIMER. J.S. Spatial distribution of modern dinoflagellate cysts in polluted estuarine sediments from Buzzards Bay (Massachusetts, USA) embayments. Marine Ecology Progress Series, v. 292, p. 23-40, 2005.

PRAUSS, M. The oceanographic and climatic interpretation of marine palynomorph phytoplankton distribution from Mesozoic, Cenozoic and Recent sections. Göttinger Arbeiten Geologie Paläontologie, n.76, p. 3-235, 2000.

PRICE, A.M.; POSPELOVA, V.; COFFIN, M.R.S.; LATIMER, J.S.; CHMURA, G.L. Biogeography of dinoflagellate cysts in northwest Atlantic estuaries. Ecology and Evolution, v. 6, n. 16 p. 5648-5662, 2016. Disponível em: http://onlinelibrary.wiley. com/doi/10.1002/ece3.2262/full. Acessado em: 19mar2017.

PRIETO, A.R. Análisis e interpretación de registros palinológicos de sucesiones aluviales de la region pampeana: revision de la vegetación y el clima durante el Pleistoceno Tardío - Holoceno. In: MARTÍNEZ, M. \& OLIVEIRA, D. (Editores), Palinología del Meso-Cenozoico de Argentina-Volumen en homenaje a Mirta Elena Quattrocchio. Publicacíon Eletónica de la Asociacíon Paleontológica Argentina, v. 16, n. 2, p. 148-167, 2016. Disponível em: http://dx.doi.org/10.5710/PEAPA.27.09. 2016.114. Acessado em: 09jan2017.

RADI, T. \& VERNAL, A. Dinocysts as proxy of primary productivity in mid-high latitudes of the Northern Hemisphere. Marine Micropaleontology, v. 68, n. 1-2, p. 84-114, 2008.

RADI, T.; de VERNAL, A.; PEYRON, O. Relationships between dinoflagellate cyst assemblages in surface sediment and hydrographic conditions in the Bering and Chukchi seas.
Journal of Quaternary Science, v. 16, n. 7, p. 667-680, 2001.

ROCHON, A.; VERNAL, A.; TURON, J-L.; MATTHIESSEN, J.; HEAD, M.J. Distribution of dinoflagellate cysts in surface sediments from the North Atlantic Ocean and adjacent seas in relation to sea-surface parameters. Special Contribution Series of the American Association of Stratigraphic Palynologists Foundation, v. 35, p. 1-152, 1999.

SOUZA, J.T. Integração dos estudos de palinofácies e palinologia com ênfase em dinocistos (cistos de dinoflagelados) em dois testemunhos do Quaternário da região de Cabo Frio - RJ/Brasil. Rio de Janeiro, 2012. 199 p. Dissertação (Mestrado em Geociências) - Instituto de Geociências, Universidade Federal do Rio de Janeiro.

STOCKMARR, J. Tablets with spores used in absolute pollen analysis. Pollen et Spores, v. 13, p. 615-621, 1971.

STUIVER, M.; REIMER, P.J.; REIMER, R.W. CALIB 7.1 [WWW program]. Belfast: 14CHRONO Centre, Queen's University Belfast, 2016. Disponível em: http://calib.org/ calib/. Acessado em: 30nov2016.

SUGUIO, K.; MARTIN, L.; BITTENCOURT, A.C.S.P.; DOMINGUEZ, J.M.L.; FLEXOR, J-M.; AZEVEDO, A.E.G. Flutuações do nível relativo do mar durante o Quaternário superior ao longo do litoral brasileiro e suas implicações na sedimentação costeira. Revista Brasileira de Geociências, v. 15, n. 4, p. 273-286, 1985.

TYSON. R.V. Sedimentary organic matter: organic facies and palynofacies. Chapman and Hall, p. 615, 1995.

VILANOVA, I.; PRIETO, A.R; STUTZ, S. Historia de la vegetación en relación con la evolución geomorfológica de las llanuras costeras del Este de la provincia de Buenos Aires durante el Holoceno. Ameghiniana, v. 43, n. 1, p. 147-159, 2006.

VILANOVA, I.; GUERSTEIN, G.R.; AKSELMAN, R.; PRIETO, A.R. Mid- to Late Holocene organic-walled dinoflagellate cysts from the northern Argentine shelf. Review of Palaeobotany and Palynology, v. 152, n 1-2, p. 11-20, 2008.

VILLWOCK, J.A.; TOMAZELLI, L.J. Geologia Costeira do Rio Grande do Sul. Notas Técnicas, n. 8, p. 1-45, 1995.

WALL, D.; DALE, B.; LOHMAN, G.P.; SMITH, W.K. The environmental and climatic distribution of dinoflagellate cysts in modern sediments from regions in the North and South Atlantic oceans and adjacent seas. Marine Micropaleontology, v. 2, p. 121-200, 1977.

WOOD, G.D.; GABRIEL, A.M.; LAWSON, J.C.; BATTEN, D.J. Palynological techniques-processing and microscopy. In: JANSONIUS, J.; MCGREGOR, D.C. (Editores). Palynology: principles and applications, v. 1. American Association of Stratigraphic Palynologists Foundation, p. 29-50, 1996.

YBERT, J-P.; SALGADO-LABOURIAU, M.L.; BARTH, O.M.; LORSCHEITTER M.L.; BARROS. M.A.DE.; CHAVES, S.A.DE.M.; LUZ, C.F.P.DA.; RIBEIRO, M.; SCHEEL R.; VICENTINI, K.F. Sugestões para padronização da metodologia empregada em estudos palinológicos do Quaternário. Revista Instituto de Geociências, v. 13, n 2, p. 47-49, 1992.

YBERT, J-P.; BISSA, W.M.; KUTNER, M. Relative sea level variations and climatic evolution in southeastern and southern Brazil during the Late Holocene. Pesquisas em Geociências, v. 28 , n. 2, p. 75-83, 2001.

ZONNEVELD, K.A.F.; MARRET, F.; VERSTEEGH, G.J.M.; BOGUS, K.B.S.; BOUIMETARHAN, I.; CROUCH, E.; DE VERNAL, A.; ELSHANAWANY, R.; EDWARDS, L.; ESPER, O.; FORKE, S.; GRØSFJELD, K.; HENRY, M.; HOLZWARTH, U.; KIELT, J-F.; KIM, S-Y.; LADOUCEUR, S.; LEDU, D.; CHEN, L.; LIMOGES, A.; LONDEIX, L.; LU, S-H.; MAHMOUD, M.S.; MARINO, G.; MATSOUKA, K.; MATTHIESSEN, J.; MILDENHAL, D.C.; MUDIE, P.J.; NEIL, H.L.; POSPELOVA, V.; QI, Y.; RADI, T.; RICHEROL, T.; ROCHON, A.; SANGIORGI, F.; SOLIGNAC, S.; TURON, 
J-L.; VERLEYE, T.; WANG, Y.; WANG, Z.; YOUNG, M. Atlas of modern dinoflagellate cyst distribution base on 2405 data points. Review of Palaeobotany and Palynology, v. 191, p. 1-197, 2013.

ZONNEVELD, K.A.F. \& POSPELOVA, V. A. Determination Key for Modern Dinoflagellate Cysts. Palynology, v. 39, n. 3, p. 387-409, 2015.

ZONNEVELD, K.A.F.; VERSTEEGH, G.; KODRANS-NSIAH, M. Preservation and organic chemistry of Late Cenozoic organic-walled dinoflagellate cysts: A review. Marine Micropaleontology, v. 68, n. 1-2, p. 179-197, 2008.

ZONNEVELD, K.A.F.; VERSTEEGH, G.J.M.; DE LANGE,

G.J. Palaeoproductivity and post-depositional aerobic organic matter decay reflected by dinoflagellate cyst assemblages of the Eastern Mediterranean S1 sapropel. Marine Geology, v. 172, n. 3-4, p. 181-195, 2001.

ZONNEVELD, K.A.F.; VERSTEEGH, G.J.M.; DE LANGE, G.J. Preservation of organic walled dinoflagellate cysts in different oxygen regimes: a 10,000 years natural experiment. Marine Micropaleontology, v. 29, n. 3-4, p. 393-405, 1997.

Submetido em 25 julho de 2017 Aceito em 3 de maio de 2019 